\title{
Astroglial TLR9 antagonism promotes chemotaxis and alternative activation of macrophages via modulation of astrocyte- derived signals: implications for spinal cord injury
}

\author{
Lun Li, Li Ni, Robert F. Heary and Stella Elkabes ${ }^{*}$ (i)
}

\begin{abstract}
Background: The recruitment of immune system cells into the central nervous system (CNS) has a profound effect on the outcomes of injury and disease. Glia-derived chemoattractants, including chemokines, play a pivotal role in this process. In addition, cytokines and chemokines influence the phenotype of infiltrating immune cells. Depending on the stimuli present in the local milieu, infiltrating macrophages acquire the classically activated M1 or alternatively activated M2 phenotypes. The polarization of macrophages into detrimental M1 versus beneficial M2 phenotypes significantly influences CNS pathophysiology. Earlier studies indicated that a toll-like receptor 9 (TLR9) antagonist modulates astrocytederived cytokine and chemokine release. However, it is not known whether these molecular changes affect astrocyteinduced chemotaxis and polarization of macrophages. The present studies were undertaken to address these issues.
\end{abstract}

Methods: The chemotaxis and polarization of mouse peritoneal macrophages by spinal cord astrocytes were evaluated in a Transwell co-culture system. Arrays and ELISA were utilized to quantify chemokines in the conditioned medium (CM) of pure astrocyte cultures. Immunostaining for M1- and M2-specific markers characterized the macrophage phenotype. The percentage of M2 macrophages at the glial scar was determined by stereological approaches in mice sustaining a mid-thoracic spinal cord contusion injury (SCI) and intrathecally treated with oligodeoxynucleotide 2088 (ODN 2088), the TLR9 antagonist. Statistical analyses used two-tailed independent-sample t-test and one-way analysis of variance (ANOVA) followed by Tukey's post hoc test. A $p$ value $<0.05$ was considered to be statistically significant.

Results: ODN 2088-treated astrocytes significantly increased the chemotaxis of peritoneal macrophages via release of chemokine (C-C motif) ligand 1 (CCL1). Vehicle-treated astrocytes polarized macrophages into the M2 phenotype and ODN 2088-treated astrocytes promoted further M2 polarization. Reduced CCL2 and CCL9 release by astrocytes in response to ODN 2088 facilitated the acquisition of the M2 phenotype, suggesting that CCL2 and CCL9 are negative regulators of $\mathrm{M} 2$ polarization. The percentage of $\mathrm{M} 2$ macrophages at the glial scar was higher in mice sustaining a SCl and receiving ODN 2088 treatment as compared to vehicle-treated injured controls.

Conclusions: TLR9 antagonism could create a favorable environment during $\mathrm{SCl}$ by supporting M2 macrophage polarization and chemotaxis via modulation of astrocyte-to-macrophage signals.

Keywords: Innate immune receptors, Toll-like receptor, Spinal cord injury, Astrocyte, Macrophage, Microglia, Chemokine, Cytokine, Chemotaxis

\footnotetext{
* Correspondence: elkabest@njms.rutgers.edu

Reynolds Family Spine Laboratory, Department of Neurosurgery, New Jersey

Medical School, Rutgers, The State University of New Jersey, 205 South

Orange Avenue, F-1204, Newark, NJ 07103, USA
}

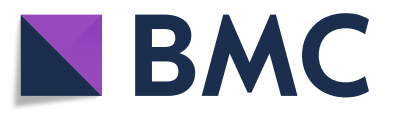

(c) The Author(s). 2020 Open Access This article is distributed under the terms of the Creative Commons Attribution 4.0 International License (http://creativecommons.org/licenses/by/4.0/), which permits unrestricted use, distribution, and

reproduction in any medium, provided you give appropriate credit to the original author(s) and the source, provide a link to the Creative Commons license, and indicate if changes were made. The Creative Commons Public Domain Dedication waiver (http://creativecommons.org/publicdomain/zero/1.0/) applies to the data made available in this article, unless otherwise stated. 


\section{Background}

Central nervous system (CNS) injury and diseases are often associated with the infiltration of immune cells into the CNS. These cells play critical roles in neuroinflammation, neurodegeneration, and paradoxically, neuroprotection [1]. The recruitment of immune cells into the affected sites is mediated by chemoattractants secreted by various cell types including those intrinsic to the CNS [2]. Astrocytes are one of the cell types that secrete potent chemoattractants $[3,4]$ such as chemokines. Peripheral macrophages are among immune system cells that are recruited to the CNS during disease and injury [5]. Macrophages show phenotypic plasticity depending on the environmental signals that are present at the affected sites [6]. Under the influence of effectors such as interferon-gamma (IFN- $\gamma$ ), macrophages acquire the classically activated M1 phenotype [7], which has been associated with detrimental effects [8], whereas effectors such as interleukin 4 (IL-4), IL-13, and transforming growth factor beta (TGF- $\beta$ ) promote the alternatively activated M2 phenotype, which has been implicated in protective and beneficial effects [9]. The M1/M2 ratio can be an important determinant of outcomes in CNS pathology [10].

Astrocytes play many fundamental roles in health and disease, including maintenance of homeostasis [11], modulation of neuronal and synaptic function [12], repair of the blood-brain barrier [13], and protection of neurons from insults [14]. Astrocytes express toll-like receptors (TLRs) [15-17], which are pattern recognition receptors (PRRs) that are best known for their role in the innate immune system in response to infections. TLRs are the first sensors of danger and recognize conserved molecular motifs in pathogens collectively called pathogen-associated molecular patterns (PAMPs). Binding of PAMPS to TLRs initiates an immune reaction to protect the host from pathogens. In addition, TLRs are important contributors to sterile inflammation that occurs in injury and diseases. In this case, endogenous ligands released by stressed, damaged, or dying cells, called danger-associated molecular patterns (DAMPs), initiate TLR signaling [18]. In addition to PAMPs and DAMPs, the availability of synthetic stimulatory or inhibitory TLR ligands has facilitated research in experimental conditions [19].

TLRs play key roles in traumatic brain and spinal cord injury (SCI) [20, 21], multiple sclerosis [22], epilepsy [23], and neuropathic pain [24]. Several TLRs have been identified in the mouse and humans [25]. Genetic deletion, stimulation, or inhibition of TLRs has led to amelioration or worsening of deficits in animal models of CNS pathology $[26,27]$, depending on the TLR, the ligand utilized, and the pathological condition investigated. This led to the conclusion that TLRs play distinct roles in the CNS, albeit further studies are necessary to elucidate the precise and unique role played by each TLR.

Studies in our laboratory have focused on TLR9. We have shown that a TLR9 antagonist, oligodeoxynucleotide 2088 (ODN 2088), alleviates functional deficits and improves histopathology in mice sustaining an SCI [28, 29]. We also reported that TLR9 immunoreactivity and mRNA are found in astrocytes, in vitro [15] and in vivo [30]. Direct inhibition of TLR9 in pure spinal cord (SC) astrocyte cultures alters the release of cytokines and chemokines [15] raising the possibility that astroglial TLR9 antagonism could modulate astrocyte-to-macrophage signals and this, in turn, could alter astrocyte-induced chemotaxis and polarization of macrophages.

The present investigations were undertaken to determine whether ODN 2088 modulates astrocyte-induced chemotaxis of macrophages, in an in vitro Transwell system that enables co-culture of pure SC astrocytes with peritoneal macrophages. We also determined whether astrocyte-derived signals modulate the phenotypic polarization of macrophages, in vitro and the percentage of M2 macrophages at the injury epicenter following SCI.

\section{Methods \\ Animals}

Adult and postnatal day 3, C57BL/6 female mice were obtained from Charles River Laboratories (Wilmington, MA, USA). TLR9 ${ }^{-/-}$mice on C57BL/6 background were bred at New Jersey Medical School, Rutgers, The State University of New Jersey. All mice were housed in a pathogen-free barrier facility on a 12:12 h light-dark cycle with water and food provided ad libitum. Sentinels were housed in the same room and periodically checked for infection. All animal protocols and experiments were approved by the Institutional Animal Care and Use Committee (IACUC) at Rutgers University and were performed in accordance with relevant guidelines and regulations.

\section{Preparation of spinal cord astrocyte cultures}

Three-day-old mouse pups were euthanized by exposure to $\mathrm{CO}_{2}$ followed by decapitation. The SCs were dissected and the meninges were carefully removed. The tissue was dissociated by trituration and the cells were plated in poly-D-lysine (Sigma-Aldrich, St. Louis, MO, USA) coated $75 \mathrm{~cm}^{2}$ culture flasks in minimum essential medium (MEM; Thermo Fisher Scientific, Waltham, MA, USA) supplemented with $15 \%$ heat-inactivated fetal bovine serum (FBS; Thermo Fisher Scientific) and 10 units/ml penicillin/streptomycin (NM-15). Cell suspensions obtained from three SCs were plated in each flask. The culture media were removed and fresh NM15 was introduced at 3-day intervals. Cultures were 
maintained in a humidified incubator with $5 \% \mathrm{CO}_{2}, 95 \%$ air at $37{ }^{\circ} \mathrm{C}$. On day 7 post-plating, after the cells reached confluence, the flasks were shaken overnight in an orbital shaker at $280 \mathrm{rpm}$ at $37^{\circ} \mathrm{C}$ to dislodge oligodendrocytes and microglia. Floating cells were removed and the adhering astrocytes were rinsed with NM-15. The cultures were then treated with $100 \mu \mathrm{M}$ Cytosine-1$\beta$-D-arabinofuranoside (AraC; Sigma-Aldrich) in NM-15 for 3 days. The astrocytes were then detached by trypsinization $(0.05 \%$ trypsin-ethylenediaminetetraacetic acid (Trypsin-EDTA); Thermo Fisher Scientific), washed twice with NM-15, and re-plated in poly-D-lysine-coated culture flasks in NM-15 at a 1:2 split ratio. Astrocytes were passaged three times as described above within a total period of 17 days and thereafter, they were trypsinized and re-plated in poly-D-lysine coated 24-well plates (Corning, Tewksbury, MA, USA), in NM-15 and incubated overnight. The medium was then gradually replaced with MEM supplemented with 1\% FBS and 10 units/ml penicillin/streptomycin. Following overnight incubation in this medium, the astrocyte cultures were used in experiments described below.

To ensure that astrocyte cultures were not contaminated by microglia, cells were fixed in $4 \%$ paraformaldehyde in $10 \mathrm{mM}$ phosphate-buffered saline (138 mM $\mathrm{NaCl}$ and $2.7 \mathrm{mM} \mathrm{KCl}$ ), pH 7.4 (PF/PBS), and immunostained with an antibody against glial fibrillary acidic protein (GFAP; Agilent Technologies, Santa Clara, CA, USA), an astrocyte marker, or ionized calcium binding adapter molecule-1 (Iba-1; Wako Laboratory Chemicals, Richmond, CA, USA), a microglial marker, using the corresponding Alexa Fluor 488- or Alexa Fluor 594tagged secondary antibodies (Thermo Fisher Scientific). The percentage of each cell type was determined by counting ten fields using a $20 \times$ objective. The astrocyte cultures were more than $99 \%$ pure.

\section{Preparation of peritoneal cavity cells}

Mouse peritoneal cavity cells were isolated from 10week-old C57BL/6 female mice as described by Ray and Dittel [31]. Briefly, mice were euthanized by exposure to $\mathrm{CO}_{2}$. The outer skin of the peritoneum was removed using scissors and forceps, whereas the inner skin of the peritoneum remained intact. Five milliliter of ice-cold sterile phosphate buffer saline (PBS; Thermo Fisher Scientific) containing 3\% FBS were injected into the peritoneal cavity. Following a gentle massage of the peritoneum, the peritoneal fluid was collected and centrifuged at $1500 \mathrm{rpm}$ for $8 \mathrm{~min}$. The precipitated cells were suspended in MEM and seeded in 24-well plates for $10 \mathrm{~min}$ to allow adherence of macrophages to the dish. MEM was then removed and the cells were incubated in MEM supplemented with 1\% FBS and 10 units/ $\mathrm{ml}$ penicillin/streptomycin. In the experiments that used inserts, the peritoneal cells were seeded and maintained in MEM supplemented with $1 \% \mathrm{FBS}$ and 10 units $/ \mathrm{ml}$ penicillin/streptomycin.

\section{Chemotaxis assay \\ Astrocyte-induced chemotaxis of peritoneal macrophages}

Astrocytes, prepared as described above, were seeded into 24-well plates at a density of $1.5 \times 10^{4}$ cells/well in NM-15 and incubated in a humidified incubator overnight. Thereafter, the medium was replaced first with NM-15/MEM containing 1\% FBS (1:1, for $8 \mathrm{~h}$ ) and subsequently, with MEM containing 1\% FBS. Following overnight incubation, cells were treated with $1 \mu \mathrm{M}$ ODN 2088 (InvivoGen, San Diego, CA, USA) or vehicle for $24 \mathrm{~h}$. Transwell inserts, containing the mouse peritoneal cavity cells, were transferred into the 24-well plate that comprised the ODN 2088- or vehicle-treated astrocytes. The co-cultures were incubated for $3 \mathrm{~h}$ at $37^{\circ} \mathrm{C}$. This period of time was sufficient for chemotaxis to the lower membrane without cell loss. The inserts were then removed and fixed in $4 \%$ PF/PBS. Cells on the upper surface of the inserts were wiped off and the cells that migrated to the lower surface of the inserts were blocked with 30\% normal goat serum (NGS; Vector Laboratories, Burlingame, CA, USA) in PBS for $1 \mathrm{~h}$ at room temperature (RT). Thereafter, cells were immunostained with F4/80 antibody (Novus Biologicals, Littleton, CO, USA; 1:500 dilution) and the corresponding Alexa Fluor 488-tagged secondary antibody. Samples were counterstained with 4',6-diamidino-2-phenylindole (DAPI) and coverslipped with ProLong Diamond antifade mountant (Thermo Fisher Scientific). In each experiment, 3-4 replicates/experimental group were used. $\mathrm{F} 4 / 80^{+}$cells in three random and non-overlapping fields of each insert were counted utilizing a Leica DMI3000 fluorescent microscope (Leica Microsystems Inc., Buffalo Grove, IL, USA) equipped with a $20 \times$ objective. Representative fluorescent images were captured on a Nikon A1R confocal microscope (Nikon Instruments Inc., Melville, NY, USA) using NIS Elements AR 4.00.07 software (Nikon Instruments Inc.)

\section{Astroglial conditioned medium-induced chemotaxis of peritoneal macrophages}

Astrocytes were prepared and treated with $1 \mu \mathrm{M}$ ODN 2088 for $24 \mathrm{~h}$ as described above. Thereafter, the astrocyte conditioned medium (CM) was transferred into a new 24-well plate. The Transwell inserts, containing the mouse peritoneal cavity cells, were placed into the 24well plate and incubated at $37{ }^{\circ} \mathrm{C}$ for $3 \mathrm{~h}$. F4/80 immunolabeling of cells and counting were performed as described above for the co-cultures. In some of the experiments, mouse chemokine ( $\mathrm{C}-\mathrm{C}$ motif) ligand 1 (CCL1) neutralizing antibody $(1 \mu \mathrm{g} / \mathrm{ml}$; R\&D Systems, 
Minneapolis, $\mathrm{MN}$, USA), rat $\mathrm{IgG}_{2 \mathrm{~A}}$ isotype control (1 $\mu \mathrm{g} / \mathrm{ml}$; R\&D Systems), or recombinant chemokines were added to the CM.

\section{Determination of macrophage polarization, in vitro}

Peritoneal cavity cells, prepared as described above, were seeded into 24 -well plates at a density of $3.5 \times 10^{5}$ cells/ well in MEM and incubated in a humidified incubator for $10 \mathrm{~min}$. Subsequently, the medium containing the non-adhering cells was removed. The adhering macrophages were cultured in MEM containing 1\% FBS (control medium), $\mathrm{CM}$ of vehicle-treated astrocytes, or $\mathrm{CM}$ of ODN 2088-treated astrocytes. In some of the experiments, polarization to the M1 phenotype was induced by adding $20 \mathrm{ng} / \mathrm{ml} \mathrm{IFN- \gamma}$ to control medium [32]. Neutralization of CCL1, CCL2, and CCL9 was achieved by adding $1 \mu \mathrm{g} / \mathrm{ml}$ of neutralizing antibodies (R\&D Systems). $\operatorname{IgG}_{2 \mathrm{~A}}(1 \mu \mathrm{g} / \mathrm{ml})$ was used as isotype control. In experiments investigating the role of CCL9 in macrophage polarization, recombinant mouse CCL9 (rmCCL9; $R \& D$ Systems) was used at the final concentration of $20 \mathrm{pg} / \mathrm{ml}$.

After 24-h incubation, macrophage cultures were fixed in $4 \% \mathrm{PF} / \mathrm{PBS}$ and immunostained with an antibody against F4/80 (Novus Biologicals; 1:500), Arginase-1 (Arg-1, MilliporeSigma, Burlington, MA, USA; 1:500), or inducible nitric oxide synthase (iNOS; Cell Signaling Technology, Danvers, MA, USA; 1:500), followed by the corresponding Alexa Fluor 488- or Alexa Fluor 594tagged secondary antibodies (Thermo Fisher Scientific), and counterstained with DAPI. The percentage of F4/ $80^{+}$macrophages in the cell cultures was determined by counting ten fields per well utilizing a Leica DMI3000 fluorescent microscope equipped with a $40 \times$ objective. Representative fluorescent images were captured on a Nikon A1R confocal microscope using NIS Elements AR 4.00.07 software.

\section{Chemokine array}

To identify the chemokines released by ODN 2088- and vehicle-treated astrocytes, the $\mathrm{CM}$ was analyzed using the Mouse Chemokine Array C1 (RayBiotech, Norcross, GA, USA) according to the manufacturer's instructions. The chemiluminescent signal was visualized using a ChemiDoc Touch Imaging System (Bio-Rad, Hercules, CA, USA) and quantified utilizing The Image Lab software (Bio-Rad). The chemokine array enabled the assessment of the following 25 chemokines: CCL1, CCL2, CCL3, CCL5, CCL9, CCL11, CCL12, CCL17, CCL19, CCL20, CCL21, CCL22, CCL24, CCL25, CCL27, chemokine (C-X-C motif) ligand 1 (CXCL1), CXCL2, CXCL4, CXCL5, CXCL9, CXCL11, CXCL12, CXCL13, CXCL16, CX3CL1.

\section{Enzyme-linked immunosorbent assay}

The concentrations of CCL1, CCL2, CCL9, TGF- $\beta$, and IL-4 in ODN 2088- or vehicle-treated astrocyte CM were quantified using enzyme-linked immunosorbent assay (ELISA) kits. CCL1, CCL2, and CCL9 ELISA kits were purchased from RayBiotech. TGF- $\beta$ and IL-4 ELISA kits were obtained from R\&D Systems. Recombinant CCL1, CCL2, CCL9, TGF- $\beta$, and IL-4 protein standards were dissolved in MEM containing 1\% FBS to ensure that $\mathrm{CM}$ and protein standards were in the same medium. In addition, CCL1 concentrations were independently measured by a second ELISA kit purchased from a different vendor (Rockland Immunochemicals; Limerick, PA, USA). The colorimetric optical densities (OD) were measured by the Infinite M200 spectrophotometer (Tecan, Morrisville, NC, USA).

\section{Spinal cord injury and intrathecal delivery of ODN 2088}

Nine-week-old female C57BL/6 mice were anesthetized with ketamine $(80 \mathrm{mg} / \mathrm{kg}$; Vedco Inc., Saint Joseph, MO, USA) and xylazine (10 mg/kg; Akorn Inc., Lake Forest, IL, USA), administered by intraperitoneal (i.p.) route. A laminectomy was performed at the eighth thoracic vertebral level (T8), and a severe contusion injury (70 kdyne force) was induced using the Infinite Horizon Impactor (Precision Systems \& Instrumentation, Lexington, KY, USA). After surgery, the mice were group-housed in cages which were maintained on a heating pad at $37{ }^{\circ} \mathrm{C}$. Immediately following surgery, mice were administered subcutaneously $1 \mathrm{ml}$ of lactated Ringer solution (Baxter, Deerfield, IL, USA), physiologic saline (Baxter), Baytril (0.05 ml; Bayer, Shawnee, KS, USA), and Buprenorphine SR (1 mg/kg; ZooPharm, Laramie, WY, USA). Antibiotics and $1 \mathrm{ml}$ saline were administered twice daily, and analgesics were administered every 3 days for 7 days. Bladders were manually expressed twice a day. Twentyfour hours post-injury (p.i.), open-field locomotor function was assessed using the Basso Mouse Scale (BMS) [33]. The inclusion criterion was a BMS score $\leq 2$ on day 1 p.i. This ensured that all subjects sustained a comparable injury. In the present study, all mice sustaining an SCI satisfied the inclusion criterion.

ODN 2088 was dissolved in endotoxin-free distilled water. Intrathecal delivery of ODN 2088 or vehicle started $24 \mathrm{~h}$ p.i. and was repeated every $48 \mathrm{~h}$ until 14 day p.i. Mice were randomly divided into treatment groups and lumbar punctures (LPs) were performed, under isoflurane $(1.0 \mathrm{l} / \mathrm{min}$ at a concentration of $3.0 \%$ in oxygen) anesthesia. A 27-gauge needle, attached to a Hamilton syringe, was inserted percutaneously into the subarachnoid space between the L5 and L6 laminae. ODN 2088 (150 ng/g body weight) or vehicle was injected in a total volume of $6 \mu \mathrm{l}$. The needle was maintained in place for $30 \mathrm{~s}$ to prevent egress. 


\section{Immunohistochemistry}

Mice were sacrificed on day 14 p.i. by transcardial perfusion with saline followed by $4 \% \mathrm{PF} / \mathrm{PBS}$. The SCs were dissected, post-fixed in 4\% PF/PBS, cryoprotected in $27 \%$ sucrose/PBS, embedded in optimal cutting temperature (OCT) compound, frozen in a dry ice-ethanol slurry, and stored at $-80{ }^{\circ} \mathrm{C}$. Thirty-micrometer-thick horizontal cryostat sections were obtained from both groups and thaw-mounted on the same slide.

Spinal cord sections were blocked with $10 \mathrm{mM}$ PBS, pH 7.4 containing $10 \%$ NGS and $0.5 \%$ Triton X-100, for $1 \mathrm{~h}$ at RT. Subsequently, they were incubated overnight at $4{ }^{\circ} \mathrm{C}$ with anti-F4/80 (Novus Biologicals; 1:500 dilution), anti-Arg1 (MilliporeSigma; 1:500 dilution), and iNOS (BD Biosciences, San Jose, CA, USA; 1:100 dilution) antibodies. Thereafter, the sections were rinsed with PBS and incubated with the corresponding Alexa Fluor 488- or Alexa Fluor 594-tagged secondary antibodies (Thermo Fisher Scientific) for $1 \mathrm{~h}$ at RT. Slides were coverslipped with ProLong Diamond antifade mountant with 4',6-diamidino-2-phenylindole (DAPI; Thermo Fisher Scientific).

\section{Stereological quantification of macrophages}

A total of four horizontal sections at $150 \mu \mathrm{m}$ intervals, scanning the injury site in the entire dorso-ventral axis were used. In each section, $500-\mu \mathrm{m}$-wide zones, immediately adjacent to the rostral and caudal border of the lesion, were delineated and analyzed. F4/80 and F4/80/ Arg-1 immunopositive cell counts were obtained using the Optical Fractionator probe of Stereo Investigator V.11.11.2 (MBF Bioscience, Williston, VT, USA) and an Olympus BX51 microscope (Olympus Inc., Melville, NY, USA) equipped with a $40 \times$ objective. The counting frame was $100 \mu \mathrm{m} \times 100 \mu \mathrm{m}$, the dissector height was $15 \mu \mathrm{m}$, and the guard zones were $2 \mu \mathrm{m}$. Fifteen percent of the contour was sampled using randomized systematic sampling protocols. In each section, the number of labeled cells was estimated based on planimetric volume calculations in Stereo Investigator. $\mathrm{F} 4 / 80^{+}$and $\mathrm{F} 4 / 80^{+} /$ Arg- $1^{+}$cell numbers were estimated and the percentage of F4/80/Arg-1-positive cells was calculated and reported. Representative fluorescent images were captured on a Nikon A1R confocal microscope with a 40× objective using NIS Elements AR 4.00.07 software.

\section{Statistical analyses}

IBM SPSS 20.1 Statistics software (Armonk, NY, USA) and GraphPad Prism 6 software (San Diego, CA, USA) were used for statistical analyses. Two-tailed independentsample $t$-test and one-way analysis of variance (ANOVA) followed by Tukey's post hoc multiple comparison test were used. A $p$ value $<0.05$ was considered to be statistically significant. All data are presented as the mean \pm standard error of the mean (SEM).

\section{Results \\ TLR9 antagonism significantly increases astrocyte-induced chemotaxis of peritoneal macrophages}

To determine whether the TLR9 antagonist ODN 2088 alters the chemoattractant properties of astrocytes, we used a Transwell co-culture system described in the "Methods" section and illustrated in Fig. 1. Astrocytes were cultured in multi-well plates. Peritoneal cavity cells were seeded in Transwell inserts equipped with a porous membrane and the inserts were introduced into the wells containing the astrocytes. In such a co-culture system, peritoneal cells can pass through the pores of the membrane and migrate from the upper surface to the lower surface of the membrane in response to a gradient of chemoattractants released by astrocytes. The number of peritoneal cells that migrate to the lower surface of the insert membrane depends on the potency of the chemoattractant gradient present in the culture wells and can be quantified after visualization of the peritoneal cells by immunocytochemistry using antibodies against specific markers.

We pretreated astrocytes with vehicle and $1 \mu \mathrm{M}$ ODN 2088 for $24 \mathrm{~h}$. We then introduced the inserts containing peritoneal cells and incubated the co-cultures for $3 \mathrm{~h}$. Subsequently, we fixed and immunolabeled the cells that crossed to the lower surface of the membrane with an antibody against F4/80, a macrophage marker. In cocultures that contained the vehicle-treated astrocytes, the number of $\mathrm{F} 4 / 80$ immunoreactive cells $\left(\mathrm{F} 4 / 80^{+}\right)$that migrated to the lower surface of the membrane was low. However, in co-cultures containing the astrocytes that were treated with ODN 2088 , the number of $\mathrm{F} 4 / 80^{+}$cells that migrated to the lower surface of the membrane was 7.2-fold higher than those exposed to vehicle-treated astrocytes (Fig. 1a; $p<0.0001$ ), suggesting that TLR9 antagonism enhances astrocyte-induced chemotaxis of macrophages.

We next determined whether the effects of ODN 2088 on astrocyte-induced macrophage chemotaxis necessitate the simultaneous presence of astrocytes and macrophages in the Transwell co-cultures and the active crosstalk between the two cell types. To address this question, we treated astrocytes with vehicle or ODN 2088, collected the $\mathrm{CM}$, and exposed the peritoneal cells plated in inserts to astrocyte $\mathrm{CM}$ for $3 \mathrm{~h}$. The number of $\mathrm{F} 4 / 80^{+}$ cells that crossed to the lower surface of the membrane was 6.9-fold higher when peritoneal cells were exposed to CM of ODN 2088-treated astrocytes compared to $\mathrm{CM}$ of vehicle-treated astrocytes (Fig. 1b; $p<0.0001$ ). These results suggested that ODN 2088 modulates astrocyte-induced chemotaxis of peritoneal macrophages 


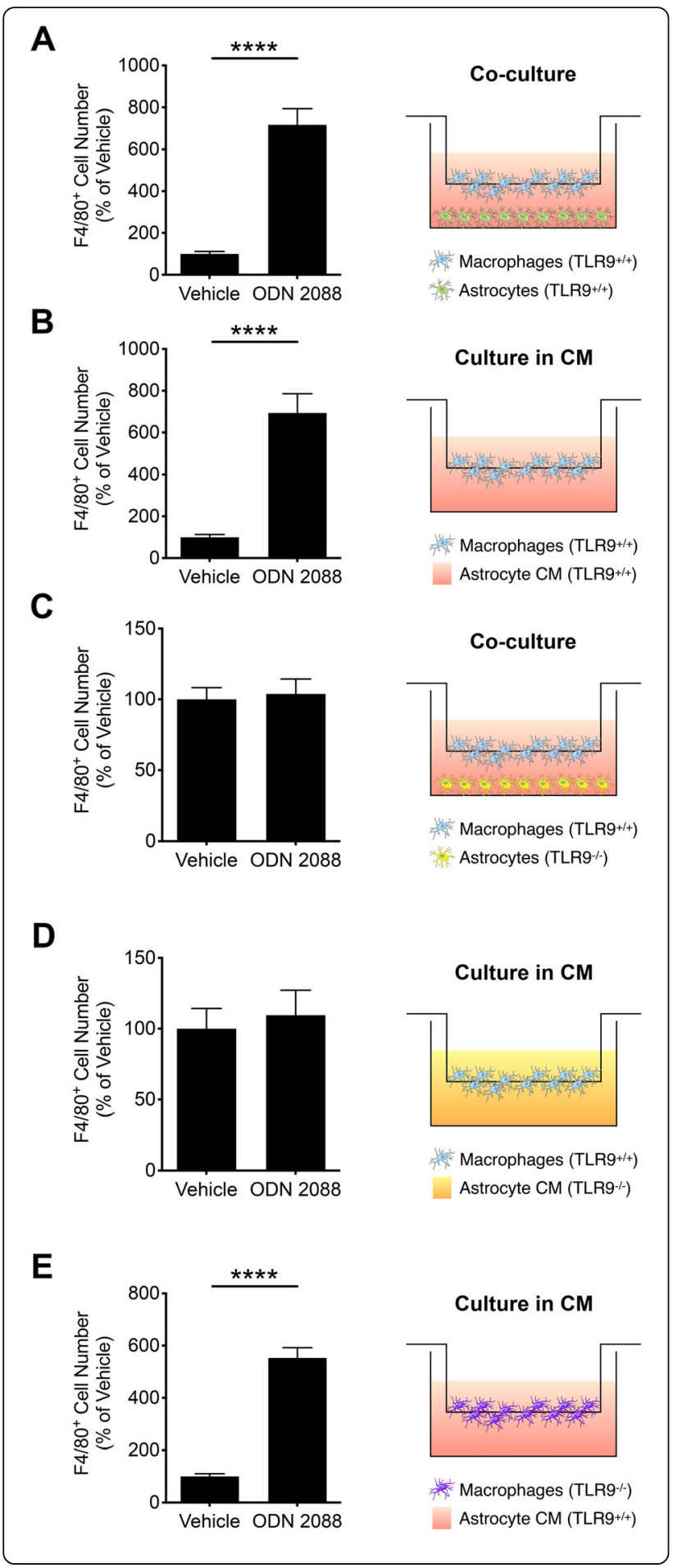

Fig. 1 ODN 2088 promotes astrocyte-induced chemotaxis of peritoneal macrophages, in vitro. a The number of $\mathrm{F} 4 / 80^{+}$cells that crossed to the lower surface of the membrane in $\mathrm{TLR}^{+/+}$astrocytemacrophage co-cultures treated with vehicle or ODN 2088 $\left[{ }^{* * * *} p<0.0001\right.$, independent-sample $t$-test, two-tailed]. b The number of $\mathrm{F} 4 / 80^{+}$cells that crossed to the lower surface of the membrane in response to CM derived from vehicle- or ODN 2088treated $\mathrm{TLR}^{+/+}$astrocyte cultures ${ }^{* * * *} p<0.0001$, independentsample $t$-test, two-tailed]. c The number of $\mathrm{F} 4 / 80^{+}$cells that crossed to the lower surface of the membrane when $\mathrm{TLR}^{-/-}$astrocyte were co-cultured with $\mathrm{TLR}^{+/+}$macrophages and treated with vehicle or ODN 2088 [ $p=0.7764$, independent-sample $t$-test, two-tailed]. $\mathbf{d}$ The number of $\mathrm{F} 4 / 80^{+}$cells that crossed to the lower surface of the membrane in response to CM derived from vehicle- or ODN 2088treated $\mathrm{TLR}^{-/-}$astrocyte cultures $[p=0.6776$, independent-sample $t$-test, two-tailed]. e The number of F $4 / 80^{+} \mathrm{TLRO}^{-1-}$ macrophages that crossed to the lower surface of the membrane in response to CM derived from vehicle- or ODN 2088-treated TLR9 ${ }^{+/+}$astrocyte cultures $\left[{ }^{* * * *} p<0.0001\right.$, independent-sample $t$-test, two-tailed]. The experiments were independently repeated three times, and the mean of three experiments $(n=3)$ is shown. Data are presented as mean \pm SEM

by modifying the release of chemoattractants by astrocytes through direct actions.

To demonstrate that the effects of ODN 2088 are dependent on the expression of TLR9 in astrocytes, peritoneal cavity cells were either co-cultured with $\mathrm{TLR9}^{-1-}$ astrocytes that were pre-treated with ODN 2088 or vehicle (Fig. 1c), or were exposed to CM of ODN 2088and vehicle-treated $\mathrm{TLR}^{-1-}$ astrocytes, as described above (Fig. 1d). There were no statistical differences in the number of $\mathrm{F} 4 / 80^{+}$cells that migrated to the lower surface of the membrane in the ODN 2088 and vehicle groups, indicating that the differential effects of ODN 2088 on astrocyte-induced chemotaxis of macrophages are dependent on the expression of TLR9 in astrocytes.

Because macrophages express TLR9 in vitro (Additional file 1-A), we undertook experiments to rule out the possibility of direct effects of ODN 2088 on macrophages. Even though astrocyte CM is collected $24 \mathrm{~h}$ after addition of ODN 2088 to the cultures, and despite the vulnerability of ODNs to degradation by nucleases released into the medium, we postulated that astrocyte CM could contain residual ODN 2088 as the phosphorothioate backbone of the antagonist confers nuclease resistance. Therefore, we ascertained that increased migration is not due to direct antagonism of macrophage TLR9 by residual ODN 2088. To address this issue, we first assessed whether ODN 2088 alone, in the absence of astrocytes, affects macrophage chemotaxis. Using the Transwell system described above, we supplemented the medium with ODN 2088 or vehicle and thereafter, we introduced the inserts containing the peritoneal cells into the wells for $3 \mathrm{~h}$. The number of $\mathrm{F} 4 / 80^{+}$cells that migrated from the upper to the lower surface of the insert membrane was not statistically different when cells 
were exposed to ODN 2088 or vehicle (Additional file 1B). In addition, we performed experiments similar to those described above by using peritoneal cavity cells isolated from $\mathrm{TLR}^{-1-}$ mice. The results obtained with $\mathrm{TLR}^{-/-}$peritoneal cells were comparable to those obtained with $\mathrm{TLR}^{+/+}$cells. The number of $\mathrm{F} 4 / 80^{+}$cells that migrated to the lower surface of the membrane was 5.5 -fold higher when $\mathrm{TLR}^{-1-}$ peritoneal cells were exposed to CM of ODN 2088-treated astrocytes compared to $\mathrm{CM}$ of vehicle-treated astrocytes (Fig. 1e; $p<0.0001$ ). These experiments ruled out the possibility that increased macrophage migration in response to $\mathrm{CM}$ of ODN 2088-treated astrocytes is due to the direct effects of the residual antagonist on macrophages.

Finally, we assessed whether CM of astrocytes treated with a TLR9 agonist, ODN $1826(1 \mu \mathrm{M})$, would have opposite, inhibitory effects on macrophage migration. We did not find significant differences in the number of F4/ $80^{+}$cells in cultures exposed to $\mathrm{CM}$ of vehicle-treated astrocytes and CM of ODN 1826-treated astrocytes (results not shown). However, it is important to emphasize that these studies were limited by the low number of cells that crossed to the lower side of the membrane in both groups, which hampered the detection of an inhibitory effect.

\section{TLR9 antagonism modulates chemokine release by astrocytes, in vitro}

Since we found that ODN 2088 modifies astrocyteinduced chemotaxis of macrophages through the release of chemoattractants into the CM, we undertook studies to determine which soluble factors could be responsible for this effect. We focused on chemokines since they are potent mediators of chemotaxis [34]. We analyzed the CM of vehicle- or ODN 2088-treated astrocytes by use of a chemokine array that enabled the screening of 25 chemokines as described in the "Methods" section. CCL1 showed the highest increase and CCL9 exhibited the most pronounced decrease in the CM of ODN 2088treated astrocytes compared to $\mathrm{CM}$ of vehicle-treated controls (Fig. 2a). In addition, CCL27 was modestly increased and CCL2, CCL20, CXCL4, CXCL12, and CX3CL1 were decreased, whereas CXCL5 was unaltered (Fig. 2a, b). The signals obtained for the other chemokines were at or below detection limit and could not be reliably quantified.

To further corroborate the results obtained by chemokine arrays, we used ELISA to quantify CCL1, CCL2, and CCL9. In agreement with the arrays, CCL9 concentrations in the CM of ODN 2088-treated astrocytes were significantly reduced by $65 \%$ compared to CCL 9 concentrations in the $\mathrm{CM}$ of vehicle-treated controls (Fig. 2c, $p<0.01)$. Similarly, CCL2 concentrations were decreased by $11 \%$ in the $\mathrm{CM}$ of ODN 2088-treated cultures compared to control CM (Fig. 2d, $p<0.05$ ). However, CCL1 levels could not be quantified by ELISA even though we used kits obtained from two different vendors and assessed several different CM preparations, which were successfully utilized to quantify CCL2 and CCL9 levels. This discrepancy could be due to differences in the sensitivity of the chemokine array versus ELISA, since in the chemokine array the signal is amplified by use of a chemiluminescent substrate.

To confirm the involvement of TLR9 in the regulation of chemokine release by astrocytes, we treated the cultures with the TLR9 agonist (ODN 1826) and assessed CCL2 and CCL9 levels in the CM by ELISA. We anticipated an opposite effect to that obtained by use of the antagonist and therefore, we expected an increase in the release of CCL2 and CCL9. As anticipated, ODN 1826 increased CCL2 and CCL9 release by 5.6-fold and 1.9fold respectively compared to vehicle-treated astrocyte CM (Additional file 2). In the case of CCL1, we anticipated a decrease in CCL1 levels in response to ODN 1826. However, as mentioned above, CCL1 levels were below the detection limit of the ELISA and could not be quantified in any of the groups.

\section{CCL1 released by ODN 2088-treated astrocytes mediates the chemotaxis of peritoneal macrophages}

The chemokine array identified CCL1 as the principal chemokine whose release was increased in response to treatment of astrocytes with ODN 2088. Therefore, we investigated whether CCL1 could be a trigger that elicits macrophage migration by ODN 2088-treated astrocytes or their CM. We addressed this question by using neutralizing antibodies to block CCL1 in astrocyte CM. Peritoneal cavity cells, seeded in Transwell inserts, were cultured with CM obtained from ODN 2088- or vehicletreated astrocytes in the presence or absence of a CCL1 neutralizing antibody. Vehicle or $\mathrm{IgG}_{2 \mathrm{~A}}$ isotype were used as controls. The number of $\mathrm{F} 4 / 80^{+}$cells that migrated to the lower surface of the membrane was 8.3fold higher when peritoneal cells were exposed to $\mathrm{CM}$ of ODN 2088-treated astrocytes compared to CM of vehicle-treated astrocytes (Fig. 3; $p<0.0001$ ). When CCL1 neutralizing antibody was introduced into the cultures containing the CM of ODN 2088-treated astrocytes, the number of $\mathrm{F} 4 / 80^{+}$cells that crossed to the lower surface of the membrane was significantly reduced by $47.84 \%$ (Fig. $3 ; p<0.0001$ ). Addition of $\mathrm{IgG}_{2 \mathrm{~A}}$ isotype did not reduce the number of $\mathrm{F} 4 / 80^{+}$immunoreactive cells that migrated to the lower surface of the membrane, confirming the specificity of the effect exerted by the neutralizing antibody (Fig. 3). These results indicated that CCL1 released by ODN 2088-treated astrocytes mediates, at least partly, the increase in macrophage chemotaxis. 
A

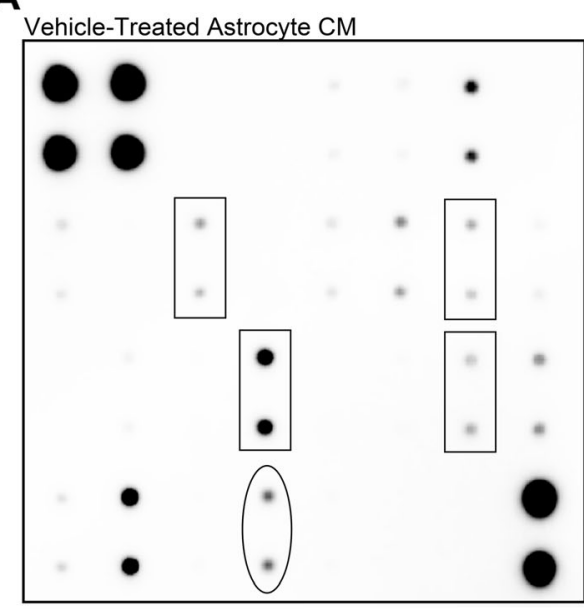

ODN 2088-Treated Astrocyte CM

B

C
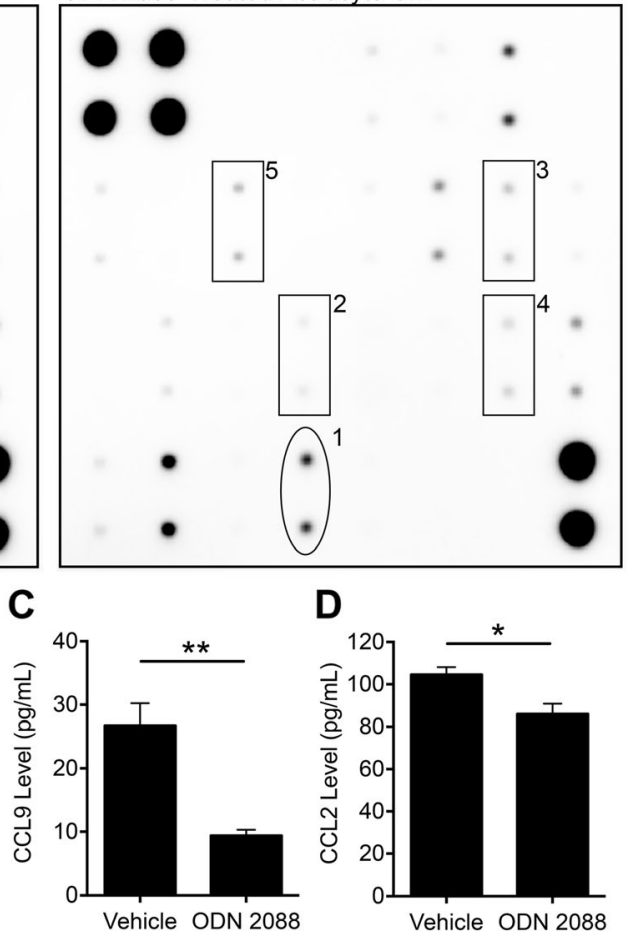

Fig. 2 ODN 2088 modulates the release of chemokines by SC astrocytes, in vitro. a Representative chemokine arrays used to detect chemokines in CM of vehicle- and ODN 2088-treated astrocytes. The chemokine arrays were independently repeated twice, showing similar results. Results from a representative experiment are shown. The dots enclosed in rectangular boxes show chemokines whose levels were decreased $(>5 \%$ difference) in the CM of ODN 2088-treated astrocytes compared to the CM of vehicle-treated astrocytes. The dots enclosed in the oval box show the chemokine whose levels were increased (> 5\% difference) in the CM of ODN 2088-treated astrocytes compared to CM of vehicle-treated astrocytes. 1: CCL1; 2: CCL9/MIP-1 Y; 3: CCL2/MCP-1; 4: CCL20/MIP-3a; 5: CX3CL1. b Densitometric quantification of the signal obtained in the chemokine array using the Image Lab software (Bio-Rad). c Quantification of CCL9 levels in CM obtained from ODN 2088- or vehicle-treated astrocytes $\left[{ }^{* *} p<0.01\right.$, independent-sample $t$-test, two-tailed]. The experiment was independently repeated four times, and the mean of 4 experiments $(n=4)$ is shown. d Quantification of CCL2 levels in CM obtained from ODN 2088- or vehicle-treated astrocytes $\left[{ }^{*} p<0.05\right.$,

independent-sample $t$-test, two-tailed]. The experiment was independently repeated three times, and the mean of 3 experiments $(n=3)$ is shown

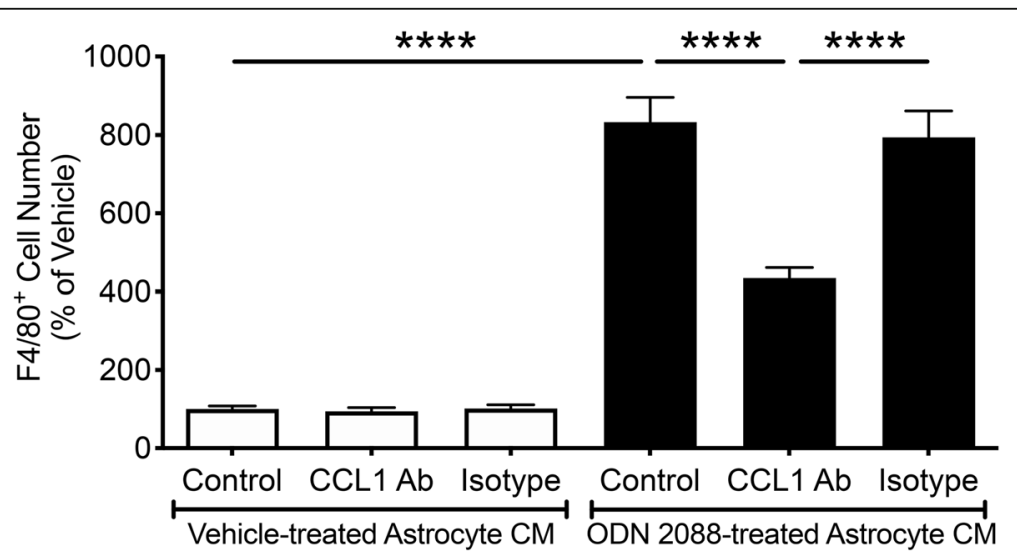

Fig. 3 CCL1 released by ODN 2088-treated astrocytes mediates the chemotaxis of peritoneal macrophages. Quantification of F4/80 ${ }^{+}$cells that crossed to the lower surface of the membrane in response to CM derived from vehicle- or ODN 2088-treated TLR9 astrocytes in the absence or presence of CCL1 neutralizing antibody or $\lg _{2 \mathrm{~A}}$ isotype control $\left[F(5,48)=81.03, p<0.0001\right.$ by one-way ANOVA, ${ }^{* * * *} p<0.0001$ by Tukey's post hoc test]. The results of three independent experiments $(n=3)$ are shown. Data are presented as mean \pm SEM 
We performed additional experiments to further corroborate the role of CCL1 in astrocyte-induced chemotaxis of macrophages. We exposed macrophages plated in inserts to control medium (MEM containing 1\% FBS) or vehicle-treated astrocyte $\mathrm{CM}$, with and without addition of recombinant mouse CCL1 (rmCCL1; $100 \mathrm{pg} / \mathrm{ml}$ ) and evaluated macrophage migration. In both experiments, the number of $\mathrm{F} 4 / 80^{+}$cells that crossed to the lower side of the membrane was increased in cultures containing rmCCL1 (Additional file 3). These studies further confirm that CCL1 mediates the chemotactic migration of macrophages.

\section{Effectors released by ODN 2088-treated astrocytes modulate macrophage phenotype}

We performed experiments to determine whether SC astrocytes modulate the polarization of macrophages into the M1 or M2 phenotype and if this capacity is altered by ODN 2088 treatment. We first focused on M1 macrophages which were identified by $\mathrm{F} 4 / 80^{+} / \mathrm{iNOS}^{+}$ double-labeling using immunocytochemistry [35]. When peritoneal cavity cells were cultured in control medium (MEM containing $1 \% \mathrm{FBS}$ ), about $88 \%$ of the cells were $\mathrm{F} 4 / 80^{+}$, indicating that the majority of the peritoneal cells in our cultures are macrophages. These cells were not immunoreactive for iNOS (Fig. 4a). Exposure to vehicle- or ODN 2088-treated astrocyte CM for $24 \mathrm{~h}$ did not induce expression of iNOS in F4 $/ 80^{+}$cells (Fig. 4b, c) demonstrating that factors secreted by astrocytes do not promote M1 polarization. In contrast, macrophages treated with IFN- $\gamma$, a trigger that promotes M1 polarization, expressed iNOS (Fig. 4d), indicating that the macrophages conserve the capacity to acquire the M1 phenotype if presented with the appropriate stimulus. In addition, we assessed whether ODN 2088-treated astrocyte CM counteracts IFN- $\gamma$-induced M1 polarization and did not find any significant effects (Fig. 4e). Finally, direct antagonism of macrophage TLR9 by addition of ODN 2088 to peritoneal cell cultures did not alter IFN- $\gamma$ induced M1 polarization (Additional file 4A).

Subsequently, we determined whether the $\mathrm{F} 4 / 80^{+}$cells express Arg-1, a marker for M2 macrophages [36]. In control medium, some of the $\mathrm{F} 4 / 80^{+}$cells were immunoreactive for Arg-1 (Fig. 5a). The percentage of $\mathrm{F} 4 / 80^{+} /$ Arg- $1^{+}$cells ranged from 10 to $21 \%$ in independent macrophage preparations. These results indicated that the majority of the $\mathrm{F} 4 / 80^{+}$cells maintained in control medium are unpolarized (M0) macrophages, but a subpopulation shows the characteristics of the M2 phenotype. Exposure of macrophage cultures to $\mathrm{CM}$ from vehicle-treated astrocytes significantly increased the percentage of F4 $/ 80^{+} / \mathrm{Arg}-1^{+}$cells (Fig. $5 \mathrm{~b}$ and d, $p<0.001$ ) albeit this effect was not consistently observed in all the experiments. However, when cells were cultured in the presence of ODN 2088-treated astrocyte CM for $24 \mathrm{~h}$, the percentage of $\mathrm{F} 4 / 80^{+} / \mathrm{Arg}-\mathrm{1}^{+}$cells was significantly increased as compared to cells that were exposed to $\mathrm{CM}$ of vehicle-treated astrocytes, and this effect was consistently observed in independent experiments (Fig. 5c, d; $p<0.001)$. Direct blockade of macrophage TLR9 by addition of ODN 2088 to macrophage cultures maintained in control medium or $\mathrm{CM}$ of vehicle-treated astrocytes did not alter the percentage of $\mathrm{F} 4 / 80^{+} / \mathrm{Arg}-1^{+}$ cells (Additional file $4 \mathrm{~B}$ and $\mathrm{C}$ ) indicating that macrophage TLR9 antagonism does not impact M2 polarization. These results suggest that ODN 2088 enhances the capacity of astrocytes to polarize macrophages into the M2 phenotype.

To corroborate these findings, we also measured expression of IL-10 in macrophage cultures exposed to CM of vehicle- or ODN 2088 astrocytes for 24 h. IL-10 is highly expressed in M2 macrophages [37]. IL-10 transcript levels were significantly increased by $50.03 \pm$ $12.89 \%(n=5 ; p<0.05)$ in macrophages treated with CM of ODN 2088-treated compared to controls. These findings further support the idea that signals derived by ODN 2088-treated astrocytes polarize macrophages into M2 phenotype.

Next, we undertook experiments to determine whether ODN 2088 influences the macrophage phenotype in vivo. We used a mouse model of SC contusion injury, which creates an inflammatory milieu at the affected site with extensive macrophage infiltration. We treated mice with ODN 2088 or vehicle until day 14 p.i., the time when a mature glial scar forms around the lesion core and we determined whether $\mathrm{F} 4 / 80^{+}$cells at the injury epicenter are iNOS or Arg-1 immunoreactive. There was a difference in the distribution of $\mathrm{F} 4 / 80^{+} / \mathrm{iNOS}^{+}$and $\mathrm{F} 4 /$ $80^{+} / \mathrm{Arg}-1^{+}$doubled-labeled cells at the lesion core and at the glial scar, which was defined as $500-\mu \mathrm{m}$-wide zones immediately caudal or rostral to the border of the lesion core (Additional file 5A) [30]. Within the lesion core, large, hypertrophic $\mathrm{F} 4 / 80^{+}$cells formed a dense network of juxtaposed cells. Both $\mathrm{F} 4 / 80^{+} / \mathrm{iNOS}^{+}$and F4/ $80^{+} /$Arg- $1^{+}$double-labeled cells could be detected at the lesion core (Additional file 5B and C). In contrast, F4/ $80^{+}$cells were scattered throughout the glial scar and some of these cells were also Arg-1 immunoreactive (Fig. 6a, b). However, we could not detect F4/80 ${ }^{+} / \mathrm{iNOS}^{+}$ double-labeled cells at the glial scar (Additional file 5D). We quantified total $\mathrm{F} 4 / 80^{+}$and $\mathrm{F} 4 / 80^{+} / \mathrm{Arg}-1^{+}$immunoreactive cells at the glial scar rostral and caudal to the lesion core and calculated the percentage of $\mathrm{F} / 80^{+} / \mathrm{Arg}$ $1^{+}$immunoreactive cells in both ODN 2088-treated injured mice and vehicle-treated injured controls. Overall, there was a $24.90 \pm 2.66 \%(p<0.01)$ decrease in total F4/ $80^{+}$cell number in ODN 2088-treated mice compared to controls. This finding was in conceptual agreement 

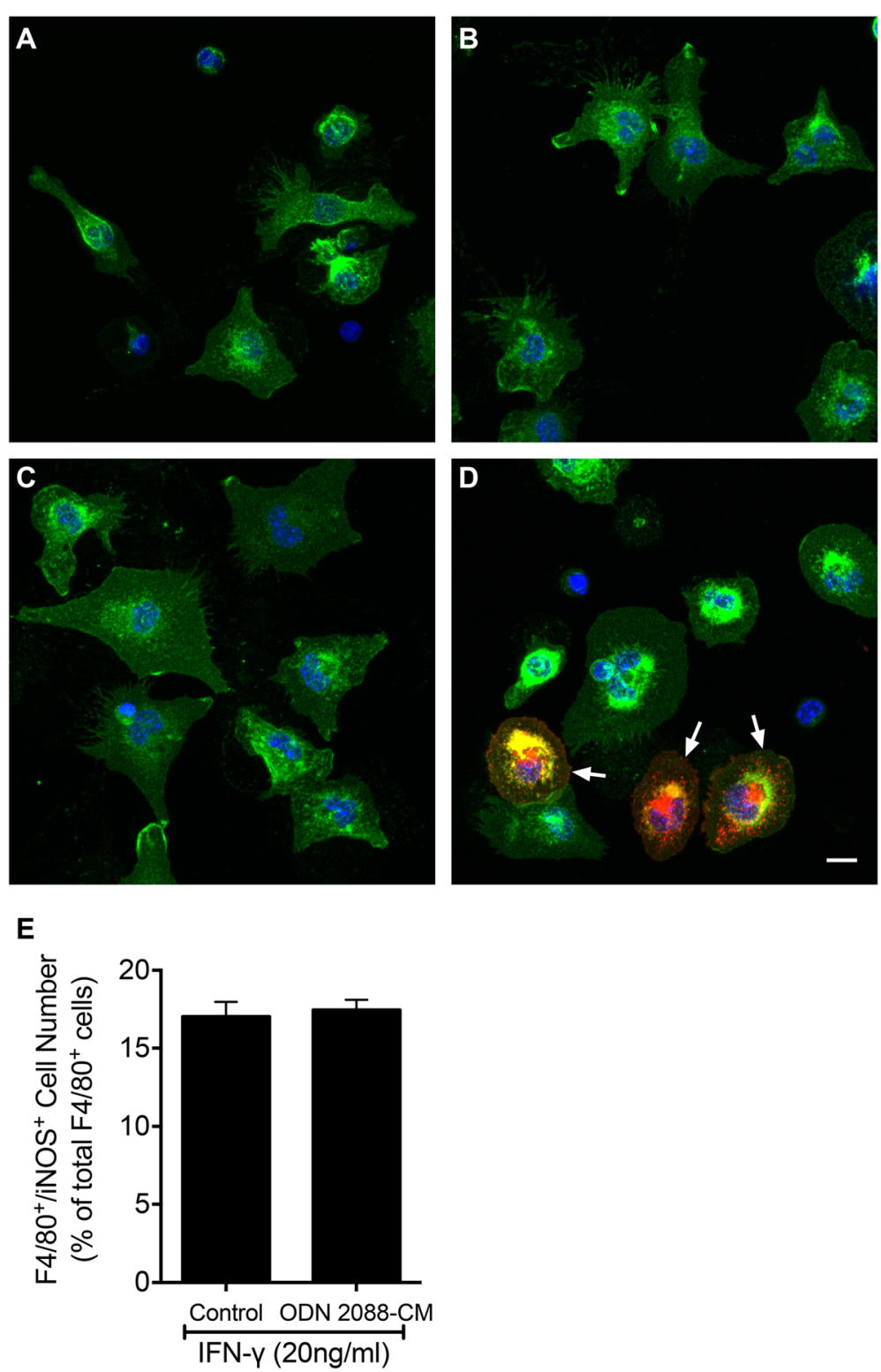

Fig. 4 CM of ODN 2088-treated astrocytes does not induce M1 macrophage polarization, in vitro. a-d Representative fluorescent images showing mouse peritoneal macrophages treated with a control medium (MEM containing 1\% FBS), b CM of vehicle-treated astrocytes, c CM of ODN 2088treated astrocytes, or $\mathbf{d} 20 \mathrm{ng} / \mathrm{ml}$ IFN- $\gamma$ in control medium. The cells were double-labeled with F4/80 (green) and iNOS (red), and counter stained with DAPI (blue). F4/80 $/ \mathrm{iNOS}^{+}$double-labeled cells (arrows) were only present in macrophage cultures treated with IFN- $\gamma$. e Addition of CM of ODN 2088-treated astrocytes (2088-CM) does not alter the number of F4/80 $/$ iNOS $^{+}$cells in IFN- $\gamma$-treated macrophage cultures $[p=0.7344$, independent-sample $t$-test, two-tailed]. The experiment was independently repeated twice, yielding similar results. Results from a representative experiment are shown. Data from the independent biological repeat of these experiments can be found in Additional file 8A. Data are presented as mean \pm SEM

with our earlier investigations showing a decrease in the number of inflammatory cells at the injury epicenter following ODN 2088 treatment [28]. However, the percentage of $\mathrm{F} 4 / 80^{+} / \mathrm{Arg}-1^{+}$double-labeled cells was significantly increased following ODN 2088 treatment: in the rostral glial scar zone of the vehicle-treated injured mice, $24 \%$ of the $\mathrm{F} 4 / 80^{+}$cells were also Arg- $1^{+}$. The percentage of $\mathrm{F} 4 / 80^{+} / \mathrm{Arg}-1^{+}$cells increased significantly to $30 \%$ in ODN 2088-treated mice (Fig. 6c, $p<0.001)$. Similarly, in the caudal glial scar zone of the vehicle-treated injured mice, $24 \%$ of the $\mathrm{F} 4 / 80^{+}$cells were also Arg- $1^{+}$. There was a significant increase in the percentage of $\mathrm{F} 4 / 80^{+} / \mathrm{Arg}-1^{+}$cells to $33 \%$ following ODN 2088 treatment (Fig. 6d, $p<0.01$ ). Thus, ODN 2088 increases the proportion of M2 cells at the glial scar following SCI. 

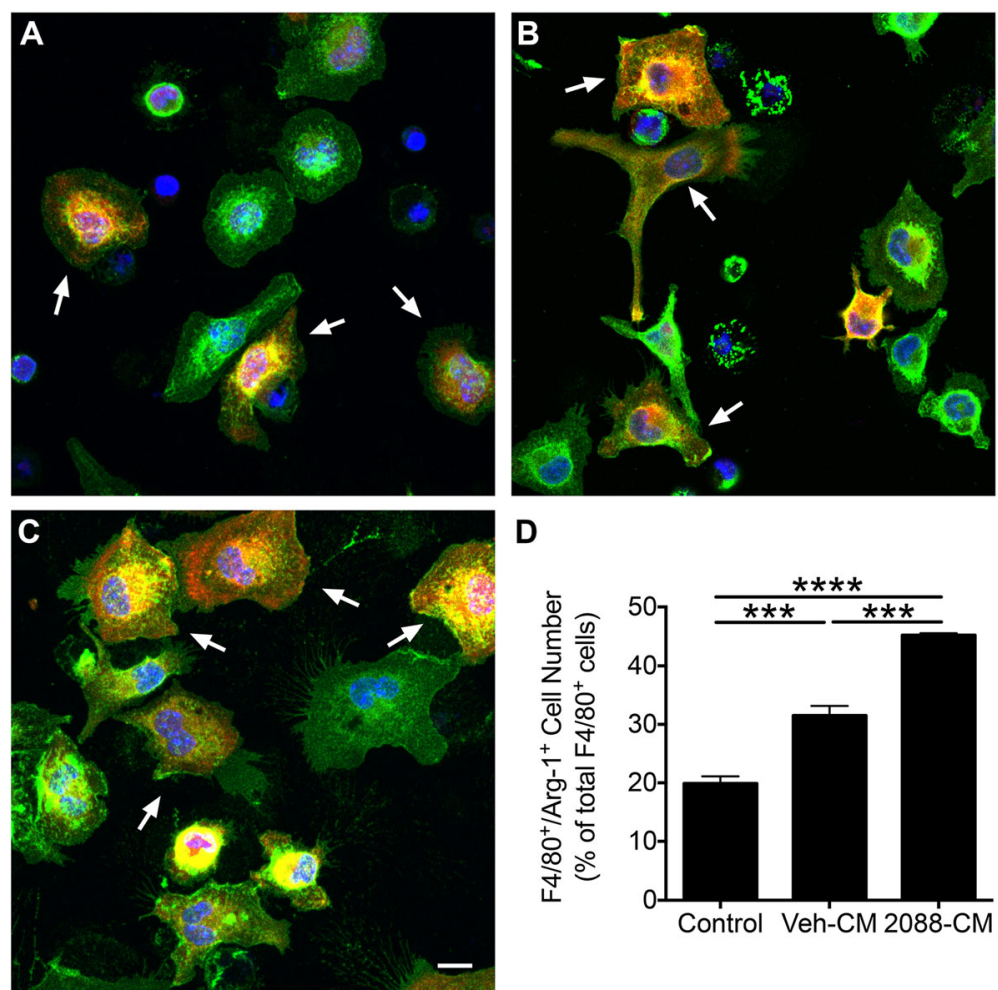

D

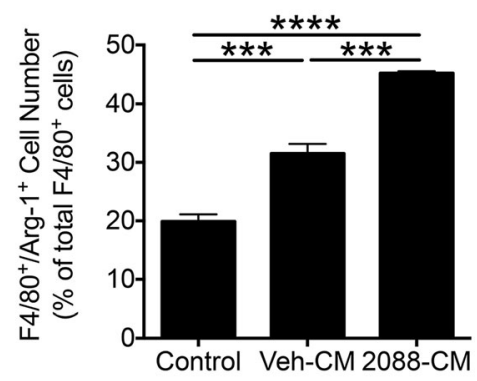

Fig. 5 CM of ODN 2088-treated astrocytes regulates M2 macrophage polarization, in vitro. a-c Representative fluorescent images showing mouse peritoneal macrophages treated with a control medium (MEM containing 1\% FBS), b CM of vehicle-treated astrocytes, or c CM of ODN 2088treated astrocytes. The cells were double-labeled with antibodies against F4/80 (green) and Arg-1 (red), and counter stained with DAPI (blue).

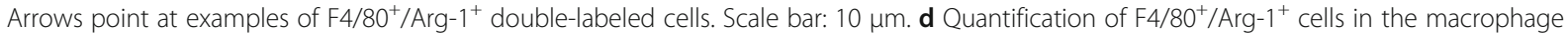
cultures maintained in control medium and in CM of vehicle- (Veh-CM) or ODN 2088 (2088-CM)-treated astrocytes $[F(2,6)=120.6, p<0.0001$ by one-way ANOVA, ${ }^{* * *} p<0.001,{ }^{* * *} p<0.0001$ by Tukey's post hoc test]. The experiment was independently repeated three times, yielding similar results. Results from a representative experiment are shown. The results obtained in additional biological repeats of these experiments can be found in Additional file $8 \mathrm{~B}$ and $\mathrm{C}$. Data are presented as mean \pm SEM

\section{Astrocyte-derived CCL2 and CCL9 are negative regulators of macrophage M2 polarization}

Cytokines and chemokines are the principal stimuli that drive the polarization of macrophages [38, 39]. TGF- $\beta 1$ is one of the major cytokines secreted by astrocytes [40] and has been shown to drive M2 polarization [41]. We first postulated that an increase in TGF- $\beta 1$ in the CM of ODN 2088-treated astrocytes could be the stimulus that enhances the M2 phenotype in our macrophage cultures. We quantified TGF- $\beta 1$ levels in the CM of vehicle- or ODN 2088-treated astrocytes by ELISA. In contrast to our postulate, TGF- $\beta 1$ concentrations in the CM of ODN 2088-treated astrocytes were significantly reduced by $17 \%$ compared to those measured in the $\mathrm{CM}$ of vehicle-treated controls (Additional file 6). This finding ruled out TGF- $\beta 1$ as the potential effector that enhances the M2 phenotype when macrophages are exposed to the CM of ODN 2088-treated astrocytes. IL-4 is another cytokine that polarizes macrophages into the M2 phenotype [42]. However, IL-4 is not secreted by astrocytes [43], but is released by microglia [44]. Even though our astrocyte cultures contain $<1 \%$ contaminating microglia, we performed experiments to assess whether these few microglia release enough IL-4 that drives macrophages into M2 phenotype. However, IL-4 concentrations in both vehicle- and ODN 2088-treated astrocyte CM were below the detection limit of the ELISA. Therefore, we could not establish IL-4 as the stimulus that drives the M2 phenotype in response to CM of ODN 2088-treated astrocyte cultures.

Subsequently, we focused on chemokines. It has previously been reported that CCL1 is required for the maintenance of the M2b phenotype [45]. As mentioned above, our chemokine arrays indicated that CCL1 levels are higher in the CM of ODN 2088-treated astrocytes than the $\mathrm{CM}$ of vehicle-treated astrocytes. Hence, we investigated whether CCL1 is the effector that promotes the M2 phenotype. We hypothesized that neutralization of CCL1 in the CM of ODN 2088-treated astrocytes by use of antibodies could prevent the increased polarization of the macrophages into the M2 phenotype. However, addition of CCL1 neutralizing antibodies to macrophage cultures 

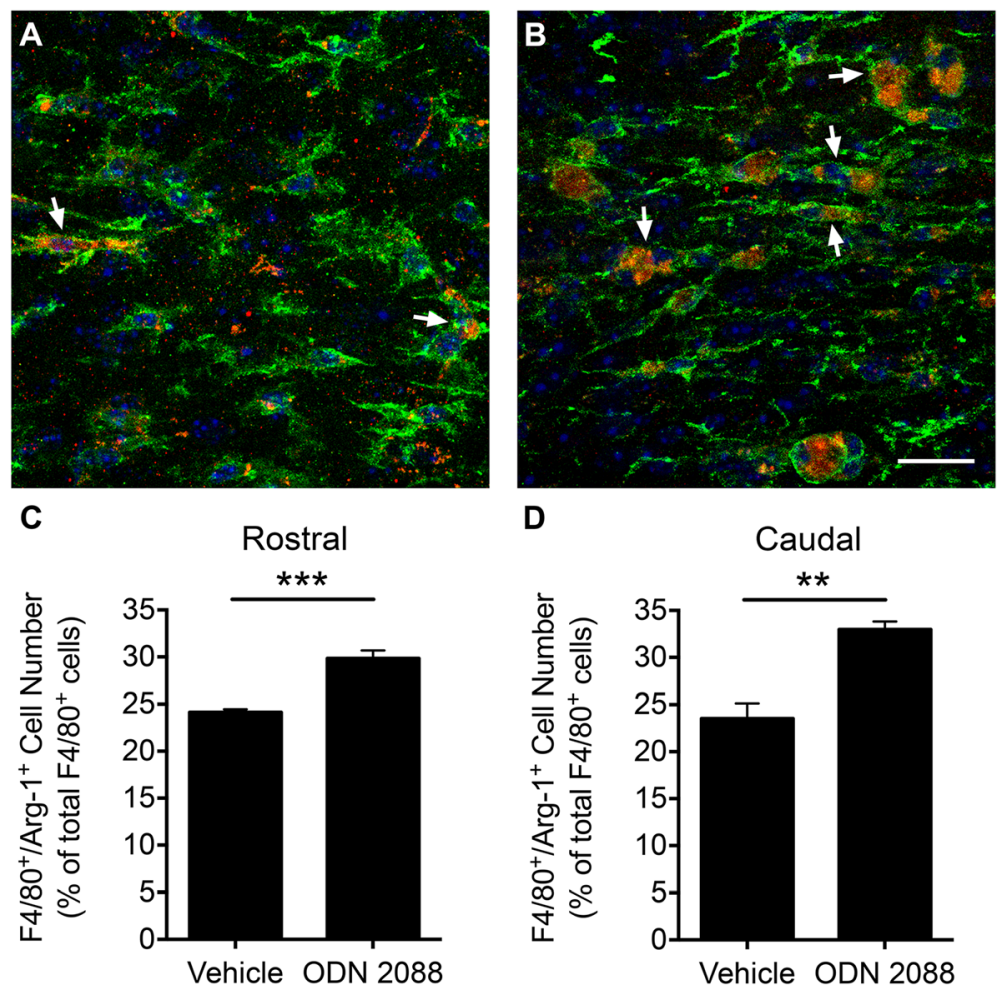

Fig. 6 Intrathecal ODN 2088 treatment increases the percentage of $\mathrm{F} 4 / 80^{+} / \mathrm{Arg}^{-1}{ }^{+}$double-labeled cells at the glial scar following SCl. Representative fluorescent images showing horizontal SC sections of mice that sustained a SCl and treated with a vehicle and $\mathbf{b}$ ODN 2088. The images were obtained from the glial scar. The sections were double-labeled with an antibody against F4/80 (green) and Arg-1 (red), and counter stained with DAPI (blue). Arrows point at examples of F $4 / 80^{+} / \mathrm{Arg}-1^{+}$double-labeled cells. Scale bar: $20 \mu \mathrm{m}$. c Percentage of F $4 / 80^{+} / \mathrm{Arg}^{-1} 1^{+}$ double-labeled cells within the 500- $\mu \mathrm{m}$-wide zone immediately adjacent to the rostral border of the lesion core ${ }^{* * *} p<0.001$, independentsample $t$-test, two-tailed]. $\mathbf{d}$ Percentage of $\mathrm{F} 4 / 80^{+} / \mathrm{Arg}-1^{+}$double-labeled cells within the 500 - $\mu \mathrm{m}$-wide zone immediately adjacent to the rostral border of the lesion core ${ }^{* *} p<0.01$, independent-sample $t$-test, two-tailed]. Data are presented as mean \pm SEM. $n=4$ mice/group

exposed to the CM of ODN 2088-treated astrocytes did not alter the percentage of $\mathrm{F} 4 / 80^{+} / \mathrm{Arg}-\mathrm{1}^{+}$cells, indicating that CCL1 is not the mediator of M2 polarization in our cultures (Fig. 7a).

These findings led us to investigate the involvement of CCL2 because a decrease in CCL2 has previously been associated with the development of the M2 phenotype [46]. As mentioned above, cytokine arrays and ELISA showed that ODN 2088 treatment reduces CCL2 release by astrocytes. To establish a link between a decrease in CCL2 and enhancement of M2 phenotype in our macrophage cultures, we added CCL2 neutralizing antibodies to vehicletreated astrocyte $\mathrm{CM}$ and assessed whether blocking CCL2 increases the percentage of $\mathrm{F} 4 / 80^{+} / \mathrm{Arg}-1^{+}$cells. In fact, neutralization of CCL2 significantly increased the percentage of $\mathrm{F} 4 / 80^{+} / \mathrm{Arg}-1^{+}$cells (Fig. $7 \mathrm{~b} ; p<0.01$ ). These results indicated that astrocyte-derived CCL2 is a negative regulator of M2 polarization and a reduction in CCL2 release by astrocytes in response to ODN 2088 fosters the development of the M2 phenotype.

We performed similar experiments with CCL9, since it was the cytokine that showed the most profound decrease in the CM of ODN 2088-treated astrocytes. When CCL9 neutralizing antibodies were added to macrophage cultures maintained in $\mathrm{CM}$ of vehicle-treated astrocytes, the percentage of $\mathrm{F} 4 / 80^{+} / \mathrm{Arg}-1^{+}$cells was significantly increased (Fig. 7c; $p<0.001$ ). Addition of $\operatorname{IgG}_{2 \mathrm{~A}}$ isotype to either vehicle- or ODN 2088-treated astrocyte CM did not alter the percentage of $\mathrm{F} 4 / 80^{+} / \mathrm{Arg}-\mathrm{1}^{+}$cells, confirming the specificity of the neutralizing antibodies (Additional file 7). These results indicated that CCL9 is another negative regulator of M2 polarization and ODN 2088 fosters the differentiation of macrophages into the M2 phenotype by reducing CCL9 release by astrocytes. To further corroborate this idea, we restored CCL9 levels in the CM of ODN 2088-treated astrocytes by addition of recombinant mouse CCL9 (rmCCL9). Supplementation of CM of ODN 2088-treated astrocytes with rmCCL9 significantly decreased the percentage of $\mathrm{F} 4 / 80^{+} / \mathrm{Arg}-1^{+}$cells in macrophage cultures (Fig. $7 \mathrm{~d} ; p<0.05$ ).

\section{Discussion}

The present investigations show, for the first time, that direct antagonism of TLR9 in SC astrocytes modulates 
A

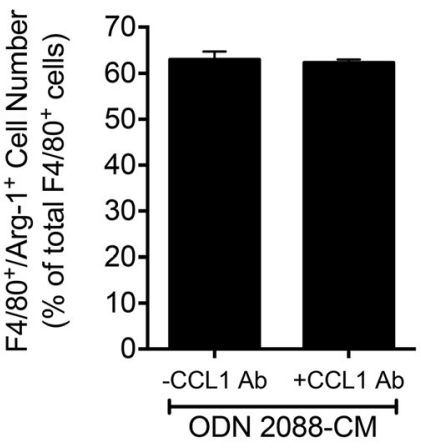

C

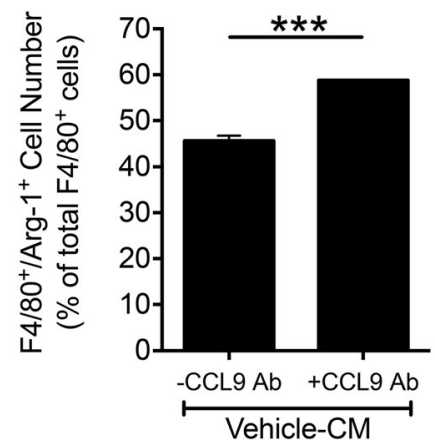

B

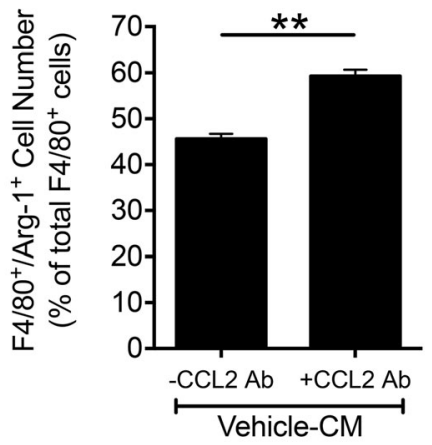

D

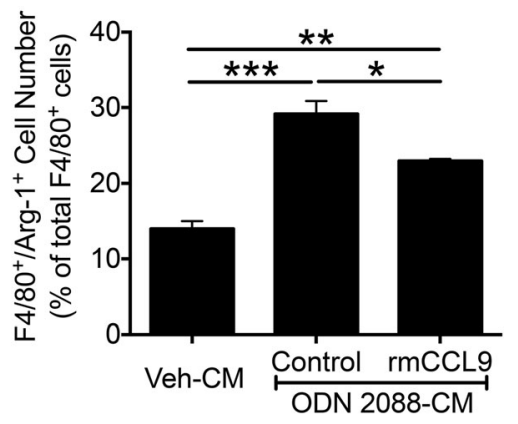

Fig. 7 Astrocyte-derived CCL2 and CCL9 but not CCL1 regulate macrophage polarization, in vitro. a Macrophage cultures were exposed to ODN 2088-treated astrocyte CM (ODN 2088-CM), in the absence or presence of CCL1 neutralizing Ab. The graph shows the quantification of the F4/ $80^{+} / \mathrm{Arg}-1^{+}$cell number expressed as percentage of total F $4 / 80^{+}$cells in the macrophage cultures $[p=0.7228$, independent-sample $t$-test, twotailed]. b Macrophage cultures were exposed to vehicle-treated astrocyte CM, in the absence or presence of CCL2 neutralizing Ab. The graph shows the quantification of the F $4 / 80^{+} / \mathrm{Arg}-1^{+}$cell number expressed as percentage of total $\mathrm{F} 4 / 80^{+}$cells in the macrophage cultures $\left[^{* *} p<0.01\right.$, independent-sample $t$-test, two-tailed]. c Macrophage cultures were exposed to vehicle-treated astrocyte CM, in the absence or presence of CCL9 neutralizing $\mathrm{Ab}$. The graph shows the quantification of the $\mathrm{F} 4 / 80^{+} / \mathrm{Arg}-1^{+}$cell number expressed as percentage of total F $4 / 80^{+}$cells in the macrophage cultures [*** $p<0.001$, independent-sample $t$-test, two-tailed]. d Macrophage cultures were exposed to vehicle-treated astrocyte CM (Veh-CM) or ODN 2088-treated astrocyte CM (ODN 2088-CM) for 24 h, with or without (control) addition of rmCCL9 (20 pg/ml). The graph shows the quantification of the $\mathrm{F} 4 / 80^{+} / \mathrm{Arg}-\mathrm{1}^{+}$double-labeled cells expressed as percent of total F4/80 ${ }^{+}$cells in macrophage cultures $[F(2,6)=53.68$, $p<0.0001$ by one-way ANOVA, ${ }^{*} p<0.05,{ }^{* *} p<0.01,{ }^{* * *} p<0.001$ by Tukey's post hoc test]. The experiments were independently repeated twice, yielding similar results. Results from a representative experiment are shown. Results obtained from additional biological repeats of these experiments can be found in Additional file 8D-G. Data are presented as mean \pm SEM

astrocyte-to-macrophage signals and this, in turn, promotes macrophage chemotaxis and polarization into the anti-inflammatory M2 phenotype, in vitro. The TLR9 antagonist modifies the pattern of chemokine release by astrocytes: increased CCL1 release supports macrophage chemotaxis, whereas decreased CCL2 and CCL9 release drives the polarization of macrophages into the M2 phenotype, suggesting that astrocyte-derived CCL2 and CCL9 are negative regulators of M2 polarization (summarized in Fig. 8). Importantly, administration of intrathecal ODN 2088 to mice sustaining a mid-thoracic SC contusion injury increases the percentage of macrophages that express a marker of the M2 phenotype at the glial scar. This finding is consistent with our earlier report showing that TLR9 antagonist modifies the milieu of the glial scar to foster neuroprotection [30].

\section{Astrocyte-induced chemotaxis of immune cells in CNS pathology: role of chemokines}

Several lines of evidence indicate that glial cells are the major source of chemokines in the CNS [47-49]. Astrocytes are among glial subtypes that release chemokines, especially in response to stimulation by cytokines [48, $50,51]$. Increased expression of chemokines in microglia and astrocytes has been associated with the migration of leukocytes into the denervated hippocampus following axotomy [49]. It has been reported that infiltration of $\mathrm{T}$ lymphocytes into the brain of patients with glioma coincides with CCL2 expression in $\mathrm{GFAP}^{+}$astrocytes [52]. The same investigators also showed that stereotactic injection of adenoviral vectors into the cerebral cortex of monkeys is paralleled by infiltration of lymphocytes into the injection site and increased CCL2 expression in 


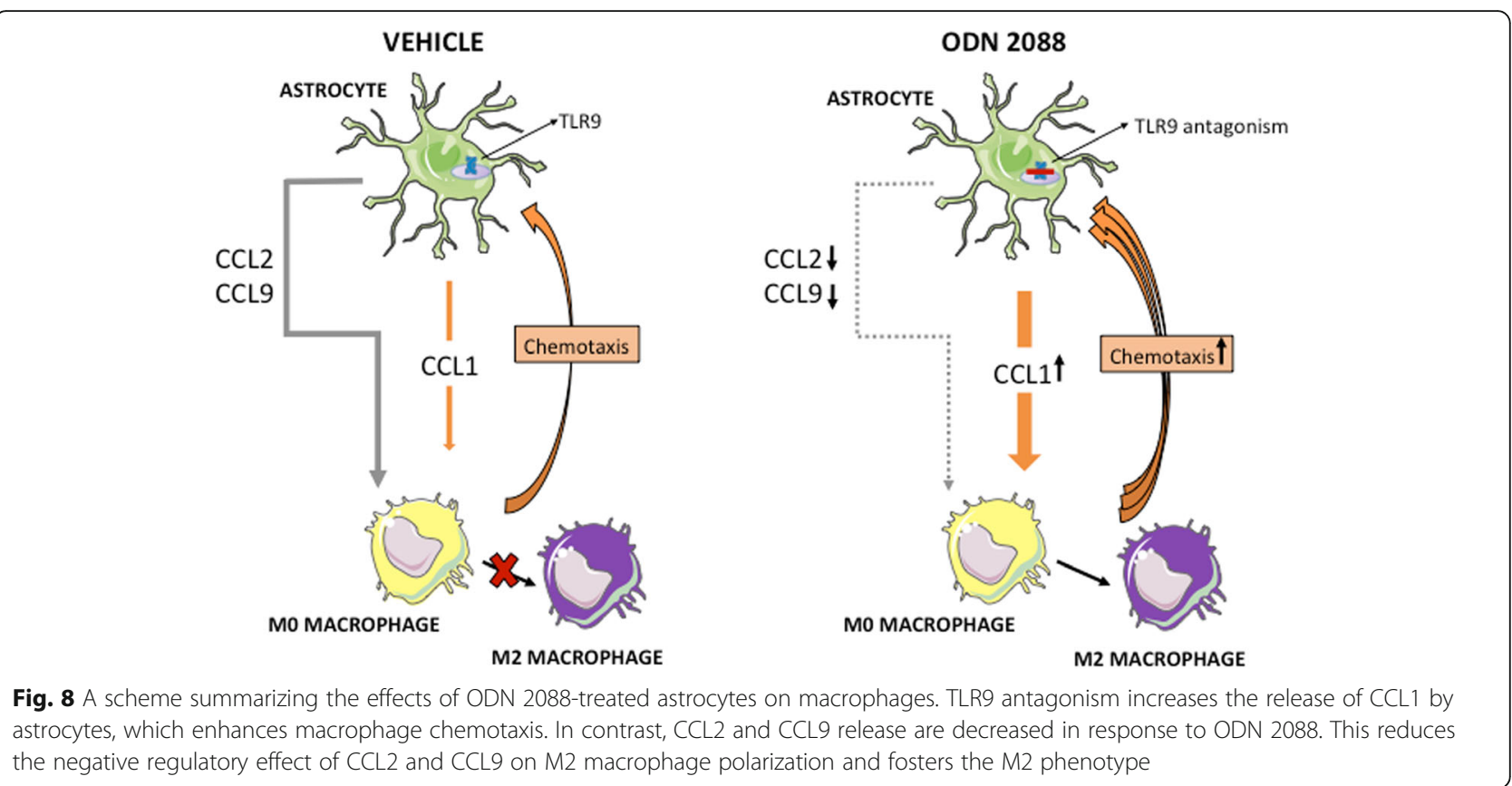

$\mathrm{GFAP}^{+}$cells [52]. Cytokine-stimulated astrocytes produce chemokines that attract dendritic cells in vitro and chemokine-expressing reactive astrocytes are localized to multiple sclerosis lesions [53]. IL-9-stimulated astrocytes release CCL20 which induces Th17 cell migration, in vitro [54]. Collectively, these reports highlight the key role played by astrocytes in promoting the chemotaxis of immune cells and their infiltration into the CNS in pathological conditions.

\section{CCL1-mediated chemotaxis of macrophages}

Recruitment of monocyte-derived macrophages into the CNS plays an important role in pathological conditions including SCI [55], multiple sclerosis, and amyotrophic lateral sclerosis [56]. In our studies, we identified CCL1 as the major chemoattractant released by ODN 2088-treated astrocytes that mediates macrophage chemotaxis, in vitro. In agreement with our findings, it has been reported that CCL1 is a potent chemoattractant for macrophages [57] and drives the chemotaxis of macrophage colony stimulating factor (M-CSF)-derived human macrophages [58] which exhibit M2 phenotype [59]. Even though CCL1 is a chemokine that is secreted primarily by $\mathrm{T}$ cells, monocytes, and mast cells [60], it is also produced by brain astrocytes and mediates the chemotaxis of $\mathrm{T}$ regulatory cells during stroke [61]. CCL1 binds its cognate receptor CCR8 which is expressed in peritoneal macrophages and modulates macrophage function including secretion of cytokines in response to stimulation of TLRs [62] and aggregation of macrophages [63].
In contrast to CCL1, CCL2 release by astrocytes was decreased in response to the TLR9 antagonist. This was an intriguing finding, especially because CCL2 is an important chemoattractant for immune cells [54]. The differential release of CCL1 and CCL2 by astrocytes in response to ODN 2088 supports the notion that TLR9 orchestrates astrocyte-to-macrophage signaling such that different macrophage functions are modulated in a specific and selective manner: increased CCL1 release promotes chemotaxis and decreased CCL2 release enables the differentiation of macrophages into the M2 phenotype. It is also important to emphasize that CCL2 plays additional roles in the CNS and has been implicated in the regulation of synaptic function [64]. It is therefore possible that astroglial TLR9 orchestrates the communication of astrocytes with other cells such as neurons through selective changes in the release of astrocytederived CCL2.

\section{Polarization of macrophages: role of chemokines}

Macrophages are heterogeneous cells that show considerable functional and phenotypic plasticity [65]. They respond to stimuli in their microenvironment by acquiring distinct phenotypes which are characterized by the expression of specific cell surface molecules, transcriptome and secretome profiles, and effector function. Conventionally, macrophages have been divided into classically activated M1 macrophages and alternatively activated M2 macrophages. M1 macrophages secrete proinflammatory cytokines, whereas M2 macrophages are characterized by immunoregulatory properties, low proinflammatory cytokine production, and secretion of anti- 
inflammatory cytokines. M2 macrophages are further classified into M2a, M2b, M2c, and M2d subtypes with distinct properties $[6,37,66,67]$.

The polarization of macrophages into M1 versus M2 phenotypes is primarily driven by cytokines. Th1 cytokines including IFN- $\gamma$ and tumor necrosis factor$\alpha$ (TNF- $\alpha$ ) induce M1 phenotype, whereas Th2 cytokines including IL-4, IL-10, and IL-13 are essential triggers that promote the M2 phenotype [65]. TGF- $\beta 1$ has also been shown to foster the M2 phenotype [41]. However, chemokines and their receptors also play a role in the polarization of macrophages [38], even though further elucidation of this role is needed. C-C chemokine receptor type 5 (CCR5) is involved in the modulation of M1 versus M2 macrophages that infiltrate the adipose tissue during obesity-induced inflammation [68]. The role of CCL2 in macrophage polarization has been controversial $[45,68-70]$. Treatment of bone marrow-derived macrophages with CCL2 did not polarize the cells into M1 or M2 phenotype but enhanced the response to IFN- $\gamma /$ lipopolysaccharide (LPS), stimuli that drive M1 polarization. High CCL2 doses suppressed the expression of Arg-1, which is a marker of M2 macrophages [70]. This latter finding is in conceptual agreement with our results suggesting that CCL2 could be a negative regulator of Arg-1 expression and M2 polarization and that a reduction in astrocyte-derived CCL2 secretion in response to ODN 2088 treatment facilitates Arg-1 expression. A link between CCL2 deficiency and increased expression of genes that code for M2 markers, including Arg-1, has also been reported in transgenic mice [46], whereas abrogation of CCL2 fostered M2 polarization and hindered the M1 polarization of adipose tissue macrophages [71]. These studies further support the notion that CCL2 is a negative regulator of M2 phenotype.

Interestingly, we also found that CCL9 could be an additional negative regulator of Arg-1 expression and M2 phenotype. To our knowledge, CCL9 release by SC astrocytes has not been reported before. Although macrophages express CCR1, the CCL9 receptor [72], the contribution of CCL9 to macrophage polarization has not been adequately defined and warrants further investigations.

\section{Increased M2 macrophages in response to ODN 2088 treatment of mice sustaining a SCI}

Our studies show that the majority of $\mathrm{F} 4 / 80^{+}$cells at the glial scar are unpolarized (M0) macrophages that express neither iNOS nor Arg-1 in both vehicle- and ODN 2088-treated injured mice. Nevertheless, intrathecal ODN 2088 significantly increased the percentage of F4/ $80^{+} /$Arg- $1^{+}$double-labeled macrophages at the glial scar.
This finding is in conceptual agreement with our in vitro data showing that ODN 2088 influences the polarization of $\mathrm{F} 4 / 80^{+}$macrophages into $\mathrm{M} 2$ phenotype via modulation of astrocyte-to-macrophage signals. However, it remains to be determined whether astrocytes are the main cell type that drives M2 polarization in ODN 2088treated injured mice. Driving macrophages into a phenotype that is more favorable for neuroprotection and repair was associated with improvement of functional deficits following SCI $[73,74]$.

The mechanisms by which ODN 2088-treated astrocytes elicit macrophage chemotaxis and polarization in vitro require further investigations. In addition to secretion of soluble molecules, extracellular vesicles (EVs) [75] shed by astrocytes could play a role in astrocyte-to-macrophage signaling. Astrocytes shed EVs constitutively, but activation of astrocytes under pathological conditions increases the shedding of astrocyte-derived EVs [76, 77]. The cargo carried by EVs includes cytokines and chemokines [78] and is variable depending on the stimulus that induces the shedding [77]. EVs have been implicated in macrophage chemotaxis [79] and macrophage polarization [80]. Following brain injury, astrocyte-derived EVs mediate the recruitment of peripheral leukocytes into the affected site [81], whereas mesenchymal stem cellderived EVs promote macrophage polarization into anti-inflammatory phenotype [80]. It is possible that such mechanisms become more effective when astrocyte TLR9 signaling is blocked by ODN 2088 leading to alterations in astrocyte-macrophage communication, affecting chemotaxis and polarization of macrophages.

\section{Conclusions}

We previously reported that TLR9 antagonism modulates astrocyte proliferation, migration, cytokine release, and astrocyte-neuron interactions, in vitro $[15,30]$. The present study expands these findings and shows that astrocyte chemoattractant properties and astrocyte-tomacrophage signaling are also modulated by TLR9 antagonism. Importantly, the investigations on mice sustaining a SCI indicate that treatment with ODN 2088 fosters M2 macrophages at the glial scar. This finding complements our earlier report demonstrating alterations in the glial scar in response to ODN 2088 [30, 82]. It remains to be determined whether the in vivo effects of ODN 2088 on macrophage polarization are the outcome of direct inhibition of TLR9 in astrocytes or mediated through effects on other cells such as neurons, microglia, and infiltrating immune cells, which also express TLR9. Our findings could have relevance for a broad range of CNS pathologies in which astrocytes and macrophages play a key role [83]. 


\section{Supplementary information}

Supplementary information accompanies this paper at https://doi.org/10. 1186/s12974-020-01748-x.

Additional file 1. ODN 2088 does not induce chemotaxis of peritoneal macrophages in the absence of astrocytes. (A) TLR9 expression in macrophages. A gel showing TLR9 transcripts in mouse peritoneal cell cultures by qRT-PCR. (B) The number of F $4 / 80^{+}$cells that crossed to the lower surface of the insert membrane when peritoneal cells were exposed to ODN 2088 in the absence of astrocytes or astrocyte CM [ $p=$ 0.2631 , independent-sample $t$-test, two-tailed]. The experiment was independently repeated six times, and the mean of six experiments $(n=6)$ is shown. Data are presented as mean \pm SEM.

Additional file 2. ODN 1826 increases CCL2 and CCL9 release by astrocytes, in vitro. (A) Quantification of CCL2 levels in CM obtained from vehicle- or ODN 1826-treated astrocytes $\left[{ }^{* *} p<0.01\right.$, independent-sample t-test, two-tailed]. (B) Quantification of CCL9 levels in CM obtained from vehicle- or ODN 1826-treated astrocytes $\left[{ }^{* * *} p<0.001\right.$, independentsample $t$-test, two-tailed]. The experiments were independently repeated four times, and the mean of 4 experiments $(n=4)$ is shown. Data are presented as mean \pm SEM

Additional file 3. Recombinant mouse CCL1 induces chemotactic migration of macrophages, in vitro. (A) The number of $\mathrm{F} 4 / 80^{+}$cells that crossed to the lower surface of the membrane in control medium (MEM with $1 \%$ FBS) with and without addition of rmCCL1. (B) The number of $\mathrm{F} 4 / 80^{+}$cells that crossed to the lower surface of the membrane in the CM of vehicle-treated astrocyte with and without addition of rmCCL1.

Additional file 4. Direct effects of ODN 2088 on macrophage polarization, in vitro. (A) ODN 2088 does not counteract the effects of IFN- $\gamma$ on macrophages. Macrophage cultures were treated with $20 \mathrm{ng} / \mathrm{m}$ IFN- $\gamma$ for $24 \mathrm{~h}$, in the presence of vehicle or $1 \mu \mathrm{M}$ ODN 2088. There were no statistical differences in the number of $\mathrm{F} 4 / 80^{+} / \mathrm{iNOS}^{+}$double-labeled cells $[p=0.425$, independent-sample $t$-test, two-tailed]. (B) Direct antagonism of macrophage TLR9 does not alter the percentage of $\mathrm{F} 4 / 80^{+} / \mathrm{Arg}-\mathrm{1}^{+}$ cells. Macrophage cultures were treated with vehicle or $1 \mu \mathrm{M}$ ODN 2088 for $24 \mathrm{~h}$. The percentage of the $\mathrm{F} 4 / 80^{+} / \mathrm{Arg}-1^{+}$cells in the macrophage cultures did not indicate statistical differences between the two groups $[p=0.823$, independent-sample $t$-test, two-tailed]. (C) Direct antagonism of TLR9 in macrophage cultures exposed to vehicle-treated astrocyte CM did not alter the percentage of $\mathrm{F} 4 / 80^{+} / \mathrm{Arg}-1^{+}$double-labeled cells. No statistical differences between the two groups were observed $[p=0.974$, independent-sample $t$-test, two-tailed]. The experiments were independently repeated twice, yielding similar results. Results from a representative experiment are shown. Data are presented as mean \pm SEM.

Additional file 5. Identification of $M 1$ and $M 2$ macrophages at the lesion core following SCl. (A) A scheme delineating the lesion core and $500-\mu \mathrm{m}$ wide glial scar region adjacent to the lesion core. (B) A representative fluorescent image showing the F4/80 (green) and iNOS (red) double-labeled cells at the lesion core. Arrows point at examples of F4/ $80^{+} / \mathrm{iNOS}^{+}$double-labeled cells. (C) A representative fluorescent image showing F4/80 (green) and Arg-1 (red) double-labeled cells at the lesion core. Arrows point at examples of $\mathrm{F} 4 / 80^{+} / \mathrm{Arg}-1^{+}$double- labeled cells. The sections in A and B are counter stained with DAPI (blue). (D) A representative fluorescent image showing the glial scar double-labeled with F4/80 (green) and iNOS (red), and counter stained with DAPI (blue). Note the absence of iNOS immunoreactivity in F4/80 cells (arrows) at the glial scar. Scale bar: $10 \mu \mathrm{m}$.

Additional file 6. Effects of ODN 2088 on TGF- $\beta 1$ release by SC astrocyte, in vitro. Quantification of TGF- $\beta 1$ levels in CM of ODN 2088- or vehicle-treated astrocytes $\left[{ }^{* *} p<0.01\right.$, independent-sample $t$-test, twotailed]. The experiment was independently repeated four times, yielding similar results. Results from a representative experiment are shown. Data are presented as mean \pm SEM.

Additional file 7. Effects of $\lg _{2 A}$ isotype control on macrophage polarization, in vitro. Macrophage cultures were exposed to (A) vehicleor (B) ODN 2088-treated astrocyte CM for $24 \mathrm{~h}$, in the presence or absence of $1 \mu \mathrm{g} / \mathrm{ml} \mathrm{lgG}_{2 A}$ isotype controls. Graphs show the quantification of the $\mathrm{F} 4 / 80^{+} / \mathrm{Arg}-1^{+}$double-labeled cells $[p=0.4376$ and $p=0.1892$ for $\mathrm{A}$ and $\mathrm{B}$, respectively, by independent-sample $t$-test, two-tailed]. The experiments were independently repeated twice, yielding similar results. Results from a representative experiment are shown. Data are presented as mean \pm SEM.

Additional file 8. Graphs showing results obtained with biological repeats in different experiments. Two additional biological repeats corresponding to the experiments shown in Fig. 4 e (A), Fig. $5 d$ ( $B$ and $C$ ), Fig. 7a (D), Fig. 7b (E), Fig. 7c (F), and Fig. 7d (G).

\section{Abbreviations}

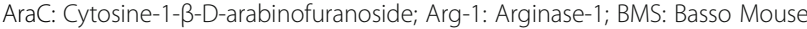
Scale; CCL: Chemokine (C-C motif) ligand; CCR: C-C chemokine receptor; CM: Conditioned medium; CNS: Central nervous system; CXCL: Chemokine (C-X-C motif) ligand 1; DAMP: Danger-associated molecular patterns; DAPI: 4',6-Diamidino-2-phenylindole; EV: Extracellular vesicle; GFAP: Glial fibrillary acidic protein; i.p.: Intraperitoneal; Iba-1: Ionized calcium binding adapter molecule-1; IFN: Interferon; IL: Interleukin; iNOS: Inducible nitric oxide synthases; LP: Lumbar puncture; LPS: Lipopolysaccharide; M-

CSF: Macrophage colony stimulating factor; NGS: Normal goat serum; OCT: Optimal cutting temperature; ODN: Oligodeoxynucleotide; p.i.: Postinjury; PAMP: Pathogen-associated molecular patterns; PRR: Pattern recognition receptors; RT: Room temperature; SC: Spinal cord; SCI: Spinal cord injury; SEM: Standard error of the mean; TGF: Transforming growth factor; TLR: Toll-like receptor; TNF: Tumor necrosis factor

\section{Acknowledgments}

The $\mathrm{TLR}^{-/-}$mice were generated by S. Akira, Ph.D. and colleagues (Osaka University, Japan). We thank Padmini Salgame, Ph.D. for providing the breeding pairs.

\section{Authors' contributions}

L.L. performed the experiments, analyzed the data, contributed to the interpretation of the results, and wrote the manuscript; L.N. contributed to the experiments; RFH contributed to the analysis and interpretation of the data; S.E. conceived the idea, directed the project, contributed to the analysis and interpretation of the data and together with L.L., wrote the manuscript. All authors read and edited the manuscript.

\section{Funding}

This work was supported by NJCSCR grants CSCR12IRG007 and CSCR17IRG007 and The Reynolds Family Spine Laboratory funds.

\section{Availability of data and materials}

The datasets used and/or analyzed during the current study are available from the corresponding author on reasonable request.

\section{Ethics approval and consent to participate}

All animal protocols and experiments were approved by the Institutional Animal Care and Use Committee (IACUC) at Rutgers University and were performed in accordance with relevant guidelines and regulations.

\section{Consent for publication}

Not applicable.

\section{Competing interests}

The authors declare that they have no competing interests.

Received: 26 August 2019 Accepted: 13 February 2020

Published online: 25 February 2020

\section{References}

1. Amor S, Puentes F, Baker D, van der Valk P. Inflammation in neurodegenerative diseases. Immunology. 2010;129:154-69.

2. Jaerve A, Muller HW. Chemokines in CNS injury and repair. Cell Tissue Res. 2012;349:229-48.

3. Hennessy E, Griffin EW, Cunningham C. Astrocytes are primed by chronic neurodegeneration to produce exaggerated chemokine and cell infiltration responses to acute stimulation with the cytokines IL-1 beta and TNF-alpha. J Neurosci. 2015;35:8411-22. 
4. Moreno M, Bannerman P, Ma J, Guo F, Miers L, Soulika AM, et al. Conditional ablation of astroglial CCL2 suppresses CNS accumulation of M1 macrophages and preserves axons in mice with MOG peptide EAE. J Neurosci. 2014;34:8175-85.

5. Herz J, Filiano AJ, Smith A, Yogev N, Kipnis J. Myeloid cells in the central nervous system. Immunity. 2017:46:943-56.

6. Sica A, Mantovani A. Macrophage plasticity and polarization: in vivo veritas. J Clin Invest. 2012;122:787-95.

7. Nathan CF, Murray HW, Wiebe ME, Rubin BY. Identification of interferongamma as the lymphokine that activates human macrophage oxidative metabolism and antimicrobial activity. J Exp Med. 1983;158:670-89.

8. Kroner A, Greenhalgh AD, Zarruk JG, Passos Dos Santos R, Gaestel M, David S. TNF and increased intracellular iron alter macrophage polarization to a detrimental M1 phenotype in the injured spinal cord. Neuron. 2014;83:1098-116.

9. Van Dyken SJ, Locksley RM. Interleukin-4- and interleukin-13-mediated alternatively activated macrophages: roles in homeostasis and disease. Annu Rev Immunol. 2013;31:317-43.

10. Ley K. M1 means kill; M2 means heal. J Immunol. 2017;199:2191-3.

11. Mahmoud S, Gharagozloo M, Simard C, Gris D. Astrocytes maintain glutamate homeostasis in the CNS by controlling the balance between glutamate uptake and release. Cells. 2019;8:184-210.

12. Allen NJ, Eroglu C. Cell biology of astrocyte-synapse interactions. Neuron. 2017:96:697-708

13. Cabezas R, Avila M, Gonzalez J, El-Bacha RS, Baez E, Garcia-Segura LM, et al. Astrocytic modulation of blood brain barrier: perspectives on Parkinson's disease. Front Cell Neurosci. 2014;8:211.

14. Belanger M, Magistretti PJ. The role of astroglia in neuroprotection. Dialogues Clin Neurosci. 2009;11:281-95.

15. Acioglu C, Mirabelli E, Baykal AT, Ni L, Ratnayake A, Heary RF, et al. Toll like receptor 9 antagonism modulates spinal cord neuronal function and survival: direct versus astrocyte-mediated mechanisms. Brain Behav Immun. 2016;56:310-24.

16. Bowman CC, Rasley A, Tranguch SL, Marriott I. Cultured astrocytes express toll-like receptors for bacterial products. Glia. 2003;43:281-91.

17. Bsibsi M, Ravid R, Gveric D, van Noort JM. Broad expression of toll-like receptors in the human central nervous system. J Neuropath Exp Neurol. 2002;61:1013-21.

18. Heiman A, Pallottie A, Heary RF, Elkabes S. Toll-like receptors in central nervous system injury and disease: a focus on the spinal cord. Brain Behav Immun. 2014;42:232-45.

19. Stunz LL, Lenert P, Peckham D, Yi AK, Haxhinasto S, Chang M, et al. Inhibitory oligonucleotides specifically block effects of stimulatory CpG oligonucleotides in B cells. Eur J Immunol. 2002;32:1212-22.

20. Kigerl KA, Popovich PG. Toll-like receptors in spinal cord injury. Curr Top Microbiol Immunol. 2009;336:121-36.

21. Hua F, Wang J, Ishrat T, Wei W, Atif F, Sayeed I, et al. Genomic profile of tolllike receptor pathways in traumatically brain-injured mice: effect of exogenous progesterone. J Neuroinflammation. 2011:8:42.

22. Gambuzza M, Licata N, Palella E, Celi D, Foti Cuzzola V, Italiano D, et al. Targeting toll-like receptors: emerging therapeutics for multiple sclerosis management. J Neuroimmunol. 2011;239:1-12.

23. Matin N, Tabatabaie O, Falsaperla R, Lubrano R, Pavone P, Mahmood F, et al. Epilepsy and innate immune system: a possible immunogenic predisposition and related therapeutic implications. Hum Vaccin Immunother. 2015:11:2021-9.

24. Kim D, Lee S, Lee SJ. Toll-like receptors in peripheral nerve injury and neuropathic pain. Curr Top Microbiol Immunol. 2009;336:169-86.

25. Takeda K, Akira S. Toll-like receptors. In: Coligan JE, et al., editors. Current protocols in immunology; 2007. Chapter 14:Unit 142.

26. Khariv V, Pang K, Servatius RJ, David BT, Goodus MT, Beck KD, et al. Toll-like receptor 9 deficiency impacts sensory and motor behaviors. Brain Behav Immun. 2013;32:164-72.

27. Kigerl KA, Lai W, Rivest S, Hart RP, Satoskar AR, Popovich PG. Toll-like receptor (TLR)-2 and TLR-4 regulate inflammation, gliosis, and myelin sparing after spinal cord injury. J Neurochem. 2007;102:37-50.

28. David BT, Ratnayake A, Amarante MA, Reddy NP, Dong W, Sampath S, et al. A toll-like receptor 9 antagonist reduces pain hypersensitivity and the inflammatory response in spinal cord injury. Neurobiol Dis. 2013;54:194-205.

29. David BT, Sampath S, Dong W, Heiman A, Rella CE, Elkabes S, et al. A tolllike receptor 9 antagonist improves bladder function and white matter sparing in spinal cord injury. J Neurotrauma. 2014;31:1800-6.
30. Li L, Ni L, Eugenin EA, Heary RF, Elkabes S. Toll-like receptor 9 antagonism modulates astrocyte function and preserves proximal axons following spinal cord injury. Brain Behav Immun. 2019;80:328-43.

31. Ray A, Dittel BN. Isolation of mouse peritoneal cavity cells. J Vis Exp. 2010;35:e1488.

32. Wang F, Zhang S, Jeon R, Vuckovic I, Jiang X, Lerman A, et al. Interferon gamma induces reversible metabolic reprogramming of M1 macrophages to sustain cell viability and pro-inflammatory activity. EBioMedicine. 2018;30:303-16.

33. Basso DM, Fisher LC, Anderson AJ, Jakeman LB, McTigue DM, Popovich PG. Basso mouse scale for locomotion detects differences in recovery after spinal cord injury in five common mouse strains. J Neurotrauma. 2006;23:635-59.

34. Sokol CL, Luster AD. The chemokine system in innate immunity. Cold Spring Harb Perspect Biol. 2015;7:a016303.

35. Draijer C, Penke LRK, Peters-Golden M. Distinctive effects of GM-CSF and MCSF on proliferation and polarization of two major pulmonary macrophage populations. J Immunol. 2019;202:2700-9.

36. Mills CD, Kincaid K, Alt JM, Heilman MJ, Hill AM. M-1/M-2 macrophages and the Th1/Th2 paradigm. J Immunol. 2000;164:6166-73.

37. Mantovani A, Sica A, Sozzani S, Allavena P, Vecchi A, Locati M. The chemokine system in diverse forms of macrophage activation and polarization. Trends Immunol. 2004;25:677-86.

38. Ruytinx P, Proost P, Van Damme J, Struyf S. Chemokine-induced macrophage polarization in inflammatory conditions. Front Immunol. 2018;9:1930.

39. Arora S, Olszewski MA, Tsang TM, McDonald RA, Toews GB, Huffnagle GB. Effect of cytokine interplay on macrophage polarization during chronic pulmonary infection with Cryptococcus neoformans. Infect Immun. 2011;79:1915-26.

40. da Cunha A, Vitkovic L. Transforming growth factor-beta 1 (TGF-beta 1) expression and regulation in rat cortical astrocytes. J Neuroimmunol. 1992:36:157-69.

41. Gong D, Shi W, Yi SJ, Chen H, Groffen J, Heisterkamp N. TGFbeta signaling plays a critical role in promoting alternative macrophage activation. BMC Immunol. 2012;13:31.

42. Hao J, Hu Y, Li Y, Zhou Q, Lv X. Involvement of JNK signaling in IL4-induced M2 macrophage polarization. Exp Cell Res. 2017;357:155-62.

43. Brodie C, Goldreich N, Haiman T, Kazimirsky G. Functional IL-4 receptors on mouse astrocytes: IL-4 inhibits astrocyte activation and induces NGF secretion. J Neuroimmunol. 1998:81:20-30.

44. Ponomarev ED, Maresz K, Tan Y, Dittel BN. CNS-derived interleukin-4 is essential for the regulation of autoimmune inflammation and induces a state of alternative activation in microglial cells. J Neurosci. 2007;27:10714-21.

45. Asai A, Nakamura K, Kobayashi M, Herndon DN, Suzuki F. CCL1 released from M2b macrophages is essentially required for the maintenance of their properties. J Leukoc Biol. 2012;92:859-67.

46. Nio Y, Yamauchi T, Iwabu M, Okada-Iwabu M, Funata M, Yamaguchi M, et al. Monocyte chemoattractant protein-1 (MCP-1) deficiency enhances alternatively activated M2 macrophages and ameliorates insulin resistance and fatty liver in lipoatrophic diabetic A-ZIP transgenic mice. Diabetologia. 2012;55:3350-8.

47. Nygardas PT, Maatta JA, Hinkkanen AE. Chemokine expression by central nervous system resident cells and infiltrating neutrophils during experimental autoimmune encephalomyelitis in the BALB/C mouse. Eur J Immunol. 2000:30:1911-8.

48. Hua L. Distinct patterns of stimulus-inducible chemokine mRNA accumulation in human fetal astrocytes and microglia. Glia. 2000;30:74-81.

49. Babcock A, Owens T. Chemokines in experimental autoimmune encephalomyelitis and multiple sclerosis. Adv Exp Med Biol. 2003;520:120-32.

50. Miyamoto Y, Kim SU. Cytokine-induced production of macrophage inflammatory protein-1alpha (MIP-1alpha) in cultured human astrocytes. J Neurosci Res. 1999:55:245-51.

51. Strack A, Asensio VC, Campbell IL, Schluter D, Deckert M. Chemokines are differentially expressed by astrocytes, microglia and inflammatory leukocytes in toxoplasma encephalitis and critically regulated by interferon-gamma. Acta Neuropathol. 2002;103:458-68.

52. Carrillo-de Sauvage MA, Gomez A, Ros CM, Ros-Bernal F, Martin ED, PerezValles $A$, et al. CCL2-expressing astrocytes mediate the extravasation of $T$ lymphocytes in the brain. Evidence from patients with glioma and experimental models in vivo. PloS one. 2012;7:e30762.

53. Ambrosini E, Remoli ME, Giacomini E, Rosicarelli B, Serafini B, Lande R, et al. Astrocytes produce dendritic cell-attracting chemokines in vitro and in multiple sclerosis lesions. J Neuropath Exp Neurol. 2005;64:706-15. 
54. Zhou Y, Sonobe Y, Akahori T, Jin S, Kawanokuchi J, Noda M, et al. IL-9 promotes Th17 cell migration into the central nervous system via CC chemokine ligand-20 produced by astrocytes. J Immunol. 2011;186:4415-21.

55. Milich LM, Ryan CB, Lee JK. The origin, fate, and contribution of macrophages to spinal cord injury pathology. Acta Neuropathol. 2019;137:785-97.

56. Mammana S, Fagone P, Cavalli E, Basile MS, Petralia MC, Nicoletti F, et al. The role of macrophages in neuroinflammatory and neurodegenerative pathways of Alzheimer's disease, amyotrophic lateral sclerosis, and multiple sclerosis: pathogenetic cellular effectors and potential therapeutic targets. Int J Mol Sci. 2018;19:831-50.

57. Toews GB. Macrophages. Asthma and Copd: basic mechanisms and clinical management. 2nd ed; 2009. p. 133-43.

58. Reimer MK, Brange C, Rosendahl A. CCR8 signaling influences toll-like receptor 4 responses in human macrophages in inflammatory diseases. Clin Vaccine Immunol. 2011;18:2050-9.

59. Fleetwood AJ, Dinh H, Cook AD, Hertzog PJ, Hamilton JA. GM-CSF- and MCSF-dependent macrophage phenotypes display differential dependence on type I interferon signaling. J Leukoc Biol. 2009;86:411-21.

60. Dembic $Z$. The cytokines of the immune system : the role of cytokines in disease related to immune response. London: Academic Press; 2015.

61. Ito M, Komai K, Mise-Omata S, lizuka-Koga M, Noguchi Y, Kondo T, et al. Brain regulatory T cells suppress astrogliosis and potentiate neurological recovery. Nature. 2019;565:246-50.

62. Oshio T, Kawashima R, Kawamura Yl, Hagiwara T, Mizutani N, Okada T, et al. Chemokine receptor CCR8 is required for lipopolysaccharide-triggered cytokine production in mouse peritoneal macrophages. PLoS One. 2014;9:e94445

63. Hoshino A, Kawamura YI, Yasuhara M, Toyama-Sorimachi N, Yamamoto K, Matsukawa A, et al. Inhibition of CCL1-CCR8 interaction prevents aggregation of macrophages and development of peritoneal adhesions. J Immunol. 2007:178:5296-304.

64. Gruol DL. Impact of increased astrocyte expression of IL-6, CCL2 or CXCL10 in transgenic mice on hippocampal synaptic function. Brain Sci. 2016;6:19-35.

65. Shapouri-Moghaddam A, Mohammadian S, Vazini H, Taghadosi M, Esmaeili SA, Mardani F, et al. Macrophage plasticity, polarization, and function in health and disease. J Cell Physiol. 2018;233:6425-40.

66. Sica A, Erreni M, Allavena P, Porta C. Macrophage polarization in pathology. Cell Mol Life Sci. 2015;72:4111-26.

67. Roszer T. Understanding the mysterious M2 macrophage through activation markers and effector mechanisms. Mediat Inflamm. 2015;2015:816460.

68. Kitade H, Sawamoto K, Nagashimada M, Inoue H, Yamamoto Y, Sai Y, et al. CCR5 plays a critical role in obesity-induced adipose tissue inflammation and insulin resistance by regulating both macrophage recruitment and M1/ M2 status. Diabetes. 2012;61:1680-90.

69. Kwon MJ, Shin HY, Cui Y, Kim H, Thi AH, Choi JY, et al. CCL2 mediates neuron-macrophage interactions to drive Proregenerative macrophage activation following preconditioning injury. J Neurosci. 2015;35:15934-47.

70. Carson WF, Salter-Green SE, Scola MM, Joshi A, Gallagher KA, Kunkel SL. Enhancement of macrophage inflammatory responses by CCL2 is correlated with increased miR-9 expression and downregulation of the ERK1/2 phosphatase Dusp6. Cell Immunol. 2017;314:63-72.

71. Rajasekaran M, Sul O, Choi E, Kim J, Suh J, Choi H. MCP-1 deficiency enhances browning of adipose tissue via increased M2 polarization. J Endocrinol. 2019:242:91-101.

72. Furuichi K, Gao JL, Horuk R, Wada T, Kaneko S, Murphy PM. Chemokine receptor CCR1 regulates inflammatory cell infiltration after renal ischemiareperfusion injury. J Immunol. 2008;181:8670-6.

73. Zhang B, Bailey WM, Kopper TJ, Orr MB, Feola DJ, Gensel JC. Azithromycin drives alternative macrophage activation and improves recovery and tissue sparing in contusion spinal cord injury. J Neuroinflammation. 2015;12:218.

74. Francos-Quijorna I, Amo-Aparicio J, Martinez-Muriana A, Lopez-Vales R. IL-4 drives microglia and macrophages toward a phenotype conducive for tissue repair and functional recovery after spinal cord injury. Glia. 2016;64: 2079-92.

75. Stahl PD, Raposo G. Extracellular vesicles: exosomes and microvesicles, integrators of homeostasis. Physiology (Bethesda). 2019;34:169-77.

76. Pascua-Maestro R, Gonzalez E, Lillo C, Ganfornina MD, Falcon-Perez JM, Sanchez D. Extracellular vesicles secreted by astroglial cells transport apolipoprotein $D$ to neurons and mediate neuronal survival upon oxidative stress. Front Cell Neurosci. 2018;12:526.
77. Datta Chaudhuri A, Dasgheyb RM, DeVine LR, Bi H, Cole RN, Haughey NJ. Stimulus-dependent modifications in astrocyte-derived extracellular vesicle cargo regulate neuronal excitability. Glia. 2020;68:128-44.

78. Stahl AL, Johansson K, Mossberg M, Kahn R, Karpman D. Exosomes and microvesicles in normal physiology, pathophysiology, and renal diseases. Pediatr Nephrol. 2019;34:11-30.

79. Kakazu E, Mauer AS, Yin M, Malhi H. Hepatocytes release ceramide-enriched pro-inflammatory extracellular vesicles in an IRE1alpha-dependent manner. J Lipid Res. 2016;57:233-45.

80. Lo Sicco C, Reverberi D, Balbi C, Ulivi V, Principi E, Pascucci L, et al. Mesenchymal stem cell-derived extracellular vesicles as mediators of antiinflammatory effects: endorsement of macrophage polarization. Stem Cells Transl Med. 2017;6:1018-28.

81. Dickens AM, Tovar YRLB, Yoo SW, Trout AL, Bae M, Kanmogne M, et al. Astrocyte-shed extracellular vesicles regulate the peripheral leukocyte response to inflammatory brain lesions. Sci Signal. 2017;10:eaai7696.

82. Pallottie A, Ratnayake A, Ni L, Acioglu C, Li L, Mirabelli E, et al. A toll-like receptor 9 antagonist restores below-level glial glutamate transporter expression in the dorsal horn following spinal cord injury. Sci Rep. 2018:8:8723.

83. Kielian T. Toll-like receptors in central nervous system glial inflammation and homeostasis. J Neurosci Res. 2006:83:711-30.

\section{Publisher's Note}

Springer Nature remains neutral with regard to jurisdictional claims in published maps and institutional affiliations.
Ready to submit your research? Choose BMC and benefit from:

- fast, convenient online submission

- thorough peer review by experienced researchers in your field

- rapid publication on acceptance

- support for research data, including large and complex data types

- gold Open Access which fosters wider collaboration and increased citations

- maximum visibility for your research: over $100 \mathrm{M}$ website views per year

At BMC, research is always in progress.

Learn more biomedcentral.com/submissions 